\title{
Shaking Table Tests on Earthquake Response Characterization of a Complex Museum Isolated Structure in High Intensity Area
}

\author{
Wenguang Liu, ${ }^{1}$ Chuan Qin, ${ }^{1}$ Yang Liu, ${ }^{2,3}$ Wenfu He, ${ }^{1}$ and Qiaorong Yang ${ }^{1}$ \\ ${ }^{1}$ Department of Civil Engineering, Shanghai University, Shanghai 200072, China \\ ${ }^{2}$ College of Civil Engineering, Tongji University, Shanghai 200092, China \\ ${ }^{3}$ Shanghai Baoye Group Co., Ltd., Shanghai 200941, China \\ Correspondence should be addressed to Wenguang Liu; liuwg@aliyun.com
}

Received 21 March 2016; Revised 17 June 2016; Accepted 6 November 2016

Academic Editor: Francesco Franco

Copyright (C) 2016 Wenguang Liu et al. This is an open access article distributed under the Creative Commons Attribution License, which permits unrestricted use, distribution, and reproduction in any medium, provided the original work is properly cited.

\begin{abstract}
Owing to special functional requirements of museum, such as great space and story height for exhibitions, large floor slab openings in plan and long span truss in elevation are becoming increasingly considered in museum design, which leads to challenges to structural safety. The aseismic performance of an isolated museum structure in high earthquake intensity regions was thus studied because of its complexity and irregularity. In order to observe the seismic characteristics and verify isolation effect, shaking table tests of a 1/30-scale structural model with and without base isolation bearings have been carried out under minor, moderate, and major earthquakes. The experimental results show that isolated structure dynamic characteristics and isolation effect are stable and storey peak acceleration responses of superstructure are less than that of fixed structure. Storey drifts of isolated structure meet required limits stipulated in Chinese design code and torsion responses of the bearings are not remarkable. It is suggested that seismic performances of complex museum structures have been effectively improved with isolation in use.
\end{abstract}

\section{Introduction}

Seismic isolation using lead rubber bearings (LRBs) has been recognized as one of the most effective approaches to protect vulnerable buildings (e.g., historical buildings, hospitals, and computer facilities) from strong earthquakes. In the past decades, numerical analyses and experimental studies conducted by many researchers [1, 2] have shown the effectiveness of seismic isolation. Actual evaluations also demonstrate the superior performance of isolated structures subjected to destructive seismic events in Northridge, USA (in 1994), and Kobe, Japan (in 1995) [3-6].

Museum is a kind of special functional public building, and its structural aseismic performances are always reduced by unique and complicated architectural design, such as large openings in floor slabs and long span truss in elevation. Structural safeties of these complex buildings are unable to realize by conventional structural design, especially in high earthquake intensity regions. The adoption of isolation could be an alternative choice for museums being capable of satisfying particular architectural functionality and structural aseismic requirements $[7,8]$.

To examine the effectiveness of isolation for complicate museum, shaking table test is reliable choice, which has been increasingly used to study the dynamic responses of different types of structures in these decades [9-12]. Iiba et al. studied 3-dimensional shaking table tests on a full-scale, two-storey house model with rubber bearing system, sliding system, and rolling system, respectively [13]. Lu et al. investigated shaking table tests on building models with a new system that combined the sliding and layered rubber bearing [14]. The effects of damping in various laminated rubber bearings on the seismic response of a 1/8 scale isolated test structure were investigated through shaking table tests [15]. The diameter of a lead plug was progressively increased so that a maximum isolator damping ratio of $24 \%$ was achieved. Dolce et al. assessed the effectiveness of four identical 1/3.3-scale, twodimensional, reinforced concrete (RC) frames, with rubberbased, steel-based, shape memory alloy-based and hybrid in an extensive program of shaking table tests $[16,17]$. Rawlinson 
et al. studied a passive gap damper to provide additional damping for isolation bearings, through numerical analysis and shaking table tests [18].

As an important parameter in the shaking table tests, the scale factors of test model and prototype structure also have been studied by many researchers. Takaoka et al. ascertained the ultimate behavior of slender base-isolated steel framed buildings in response to buckling fracture in laminated rubber bearings based on 1/9 scaled model shaking table tests [19]. Kikuchi et al. conducted earthquake simulation tests of a 1/2.5-scale model of an existing base-isolated, threestory reinforced concrete building [20], and Hwang and Hsu conducted uniaxial, biaxial, and triaxle shaking table tests to study the seismic response of a $1 / 2.5$-scale three-story baseisolated steel structure [21]. The analytical and experimental results of a $1 / 3$ scaled model of a reinforced concrete soft single storey structure mounted on natural rubber-based isolators and subjected to uniaxial seismic motion were investigated [22].

In recent studies, the aspect ratio effects on isolated structures have also been analyzed using shaking table tests. Chung et al. evaluated the effectiveness of base isolation systems for low-rise structure against severe seismic loads through the shaking table tests [23]. Miyama and Masuda conducted a shaking table test on high-aspect-ratio models of base-isolated buildings [24]. He et al. compared the seismic responses of large and small aspect ratio isolated buildings using a 1/30 scaled isolated model [25].

To achieve accurate seismic performances of isolated structure, some full-scale isolated models are used by researchers in the shaking table tests. Kasai et al. studied realistic 3D shaking table tests of full-scale building specimens utilizing the new schemes to assess performance of the building with passive control and base isolation schemes [26]. A 5-story steel moment frame building was tested at E-Defense in August 2011 with three different support configurations: a triple friction pendulum isolation system and lead rubber bearings in combination with cross linear bearings and in the fixed-base condition [27]. A base-isolated 2 -story specimen for shaking table tests was first designed and cyclic tests of laminated rubber bearings and $\mathrm{UH}$ dampers implemented in the base isolating systems were carried out [28].

Besides common civil buildings, isolation bearings are also used to protect other constructions, such as industry facilities, liquid storage tanks, and some public buildings [29]. A five-storied, bench-mark model isolated with rubber bearings was studied for various earthquakes, and the varying efficiency of the isolation system was demonstrated [30, 31]. Paulson et al. examined the experimental results of the effectiveness of base isolators for reducing the seismic demands of a one-fourth scaled model of a masonry structure [32]. Sato et al. conducted a series of shaking table tests using a reduced scale model of a demonstration fast breeder reactor plant with three types of base isolation system [33]. Shaking table tests were performed using a small-scale arch model supported by the base isolation [34]. Tomaževič et al. investigated the efficiency of improving the seismic resistance of old masonry buildings by means of seismic isolation and

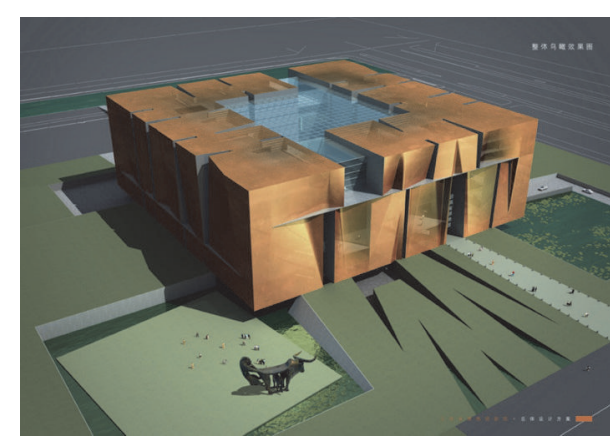

FIgURE 1: Architectural rendering of museum structure.

confining the structure with CFRP laminate trips by using shaking table tests [35].

Shaking table test has become a powerful tool for researchers and designers to examine the dynamic performance of isolation systems of high-aspect-ratio buildings, irregular structures, and some crucial constructions. These years, growing amount of complex structures have been built in high intensity area, and their seismic safeties under severe earthquakes are hard to satisfy according to conventional structural design. As a functional public building, museum's aseismic behaviors are always reduced by its large openings in floor slabs and long span truss in elevation. It is necessary for these complex structures taking shaking table tests to verify safety of conventional structural design and examine the effectiveness of isolation design. The objective of this paper is to assess seismic behaviors of such a seismically isolated museum structure called New Yunnan Provincial Museum, which has been attacked by Ludian earthquake in 2014. Brief introduction and primary achievements of the test has been summarized in [36], and more details and complete test analysis are shown in this paper.

The paper presents a shaking table test on a $1 / 30$ scale model of 7-storey concrete-steel isolated structure with irregularities in both plan and elevation. A series of simulated ground motions, such as El Centro 1940, Tangshan 1976, Northridge 1940, and an artificial record, were included in test seismic loads. Dynamic properties, such as accelerations, displacements, and torsion responses, of the model were measured during the test.

\section{Descriptions of the Building Structure}

\subsection{Prototype Building Structure. New Yunnan Provincial} Museum structure (as shown in Figure 1) is a 7-storey concrete-steel structure with a $104 \mathrm{~m}$ by $104 \mathrm{~m}$ floor plan and $37.4 \mathrm{~m}$ in total height. As shown in Figure 3, the large span atrium of $40 \mathrm{~m} \times 40 \mathrm{~m}$ dimensions is placed in first three layers. Above the large span atrium, steel truss ceiling is designed at the height between 4th and 5th floor, and three layers of steel suspensions are slung under it as exhibition room of historical relics. The steel truss ceiling and suspension system together mean the so-called "Treasures fill the house," which has a negative impact on seismic behavior of the museum structure. 
TABLE 1: Details of the museum prototype structure.

\begin{tabular}{|c|c|c|c|c|c|c|c|}
\hline \multicolumn{2}{|c|}{ Floor } & \multirow[b]{2}{*}{ Structure form } & \multicolumn{3}{|c|}{ Structure frame $(\mathrm{mm})$} & \multicolumn{2}{|c|}{ Materials } \\
\hline Floor number & $\begin{array}{l}\text { Building height } \\
(\mathrm{m})\end{array}$ & & Column & Beam & Slab & Steel & Concrete \\
\hline Roof & 37.4 & Steel truss & $\begin{array}{c}390 \times 300 \times \\
10 \times 16\end{array}$ & $500 \times 200 \times 10 \times 16$ & l & Q345B & l \\
\hline $\begin{array}{l}\text { "Treasures fill the } \\
\text { house" }\end{array}$ & 33.2 & \multicolumn{6}{|c|}{$\begin{array}{c}\text { Chords: } 450 \times 16 \text {; webs: } 351 \times 16 \text {; } \\
\text { suspenders: } 299 \times 10\end{array}$} \\
\hline 5 th F & 33.9 & $\begin{array}{l}\text { Reinforced concrete } \\
\text { (RC) }\end{array}$ & $700 \times 700$ & $800 \times 600 / 800 \times 500$ & 150 & \multirow{7}{*}{$\begin{array}{c}\text { Q345B } \\
\text { HRB335 } \\
\text { HRB400 }\end{array}$} & $\mathrm{C} 40$ \\
\hline 4th F & 30.4 & \multirow{6}{*}{$\begin{array}{l}\text { Concrete filled steel } \\
\text { tubular (CFST) }\end{array}$} & & & & & C45 \\
\hline $3 \mathrm{rd} \mathrm{F}$ & 26.6 & & $1500 \times 1500$ & $1400 \times 1000 / 1200 \times 800$ & 120 & & \\
\hline 2nd F & 22.8 & & $1200 \times 900$ & $1000 \times 700 / 1000 \times 600$ & & & \\
\hline 1st F & 15.2 & & $1000 \times 1000$ & & 150 & & C50 \\
\hline-1 st F & 7.6 & & & & & & \\
\hline$-2 n d F$ & / & & & l & 400 & & \\
\hline
\end{tabular}

Note: (1) Concrete filled steel tubular sections: column: $h_{c 1} \times t_{c 1}$; beam: $h_{b 1} \times t_{b 1}$; (2) reinforced concrete sections: column: $h_{c 2} \times t_{c 2}$; beam: $h_{b 2} \times t_{b 2}$; (3) steel truss sections: column/beam: $h_{t} \times b_{t} \times t_{t 1} \times t_{t 2}$; chords/webs/suspenders: $d_{p} \times b_{p} ;$ (4) floor slab thickness: $h_{f}$.

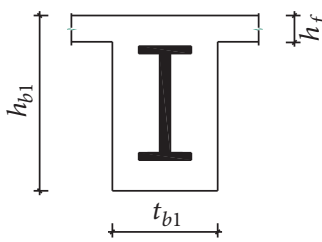

(a)

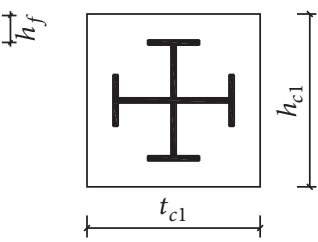

(b)

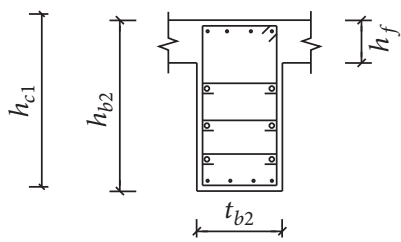

(c)

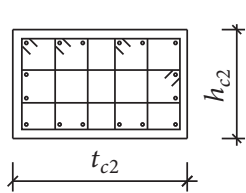

(d)

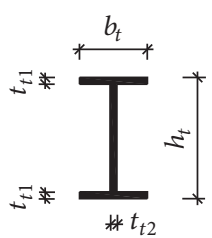

(e)

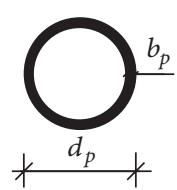

(f)

FIGURE 2: Sections of structural members used in the museum structure: (a) beam section of CFST; (b) column section of CFST; (c) beam section of RC; (d) column section of RC; (e) H-shaped steel member section; (f) sections of chords, webs, and suspenders used in steel truss.

TABLE 2: Mechanical properties of materials used in museum prototype structure.

\begin{tabular}{lc}
\hline Materials & Mechanical properties $\left(\mathrm{N} / \mathrm{mm}^{2}\right)$ \\
\hline Steel & $f=310, f_{y}=345$ \\
Q345B & $f=300, f_{y}=335$ \\
HRB335 & $f=360, f_{y}=400$ \\
HRB400 & \\
\hline Concrete & $f_{c k}=26.8$ \\
C40 & $f_{c k}=29.6$ \\
C45 & $f_{c k}=32.4$ \\
C50
\end{tabular}

Note: $f=$ steel strength design value; $f_{y}=$ steel yielding strength; $f_{c k}=$ concrete axial compressive strength.

There are three structure forms employed in the prototype structure: concrete filled steel tubular (CFST) in underground and first four layers, reinforced concrete (RC) in fifth layer, and steel truss in "Treasures fill the house," as shown in Table 1. Sketches and details of their structural member sections could be achieved in Figure 2 and Table 2. Mechanical properties of steel and concrete materials used in prototype building are listed in Table 2.

According to the Chinese Code for Seismic Design of Buildings (CSDB, GB 50011-2010) [37], the site category of New Yunnan Provincial Museum is set II and its classification of design earthquake is the second set. Due to the seismic intensity 8 for the museum structural analyses and design, the peak accelerations (PGAs) corresponding to earthquakes of minor, moderate, and major levels are specified to be $0.07 \mathrm{~g}$, $0.2 \mathrm{~g}$, and $0.4 \mathrm{~g}$, respectively.

2.2. Structural Irregularities. According to the Chinese Code for Seismic Design of Buildings (CSDB) and Chinese Technical Specification for Concrete Structures of Tall Buildings (JGJ3-2010) [38], three irregular characteristics of the building are summarized as follows.

(1) As shown in Figure 3, a large floor slab opening in plan is designed as atrium in the museum. The minimum effective widths of floor slabs in first three layers are only $38.7 \%$ and $37.2 \%$ of total width of diaphragm in the N-S and E-W directions, which are far less than the limit value $50 \%$ required in CSDB. The minimum values of the fifth floor and roof are only $13.8 \%$ and $27.6 \%$ in each direction. 


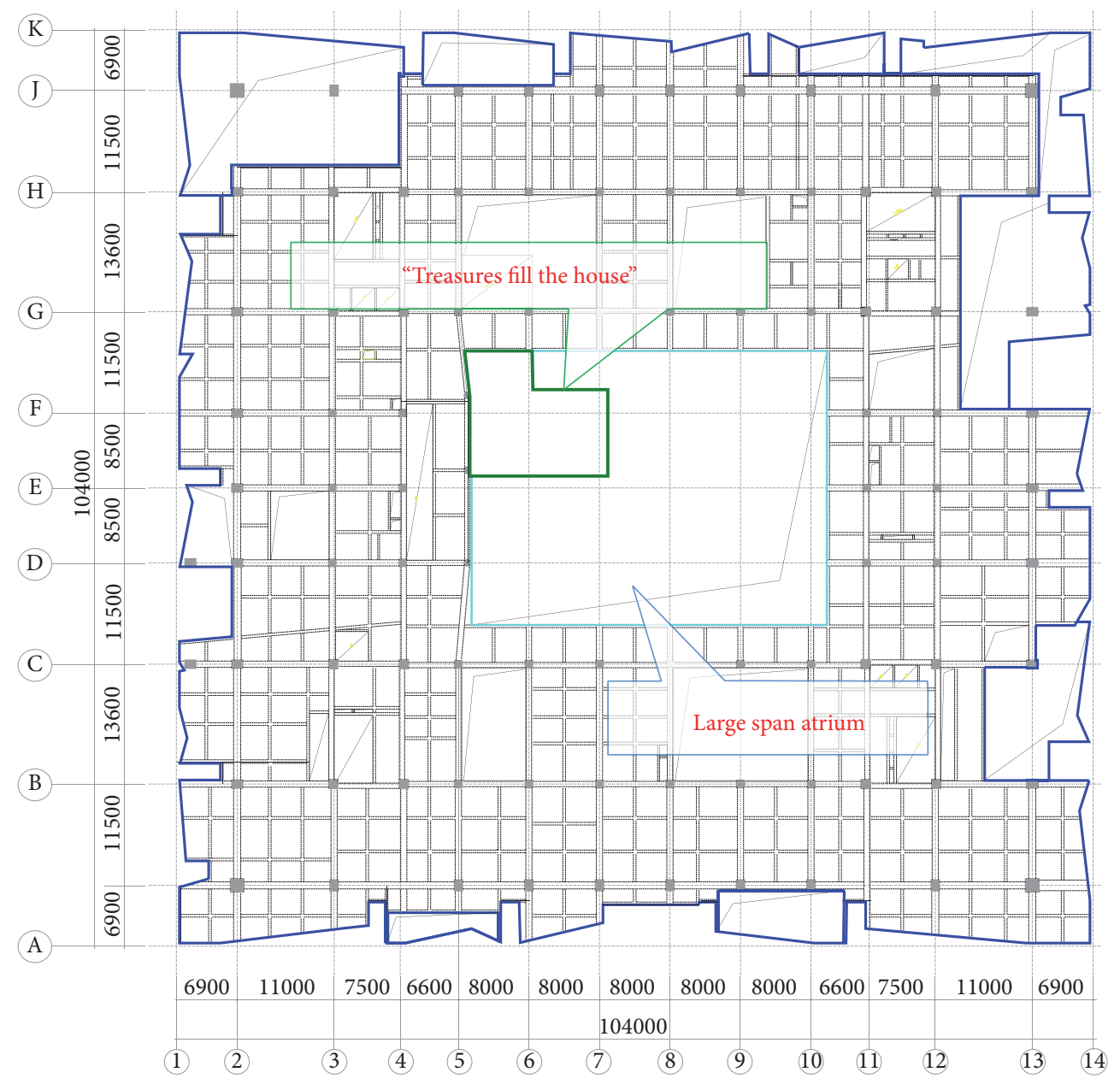

FIGURE 3: Structural plan layout of typical floor (unit: $\mathrm{mm}$ ).

These irregular characteristics are classified as "diaphragm discontinuity" according to CSDB.

(2) In structural design, several frame columns at axes $\mathrm{H}$ and $\mathrm{D}$ are only located in first four layers and no upward extension to fifth and roof layer. Column underpin is used to transfer lateral internal forces to lower layers. These irregular characteristics are classified as "discontinuity in vertical antilateral-force members" in CSDB.

(3) As the navy blue parts shown in Figure 3, cantilever slabs are designed for much more exhibition space. The peripheral cantilever slabs and beams from the underground -1 st floor to the 4 th floor are about $6 \mathrm{~m}$ and cantilever spans of $4 \mathrm{~m}$ around atrium are placed from the second floor to the fourth floor. As shown in Figures 4 and 5, another $8 \mathrm{~m}$ cantilever landscape platform at the second story is set in the atrium. These large cantilevers in design are classified as "large cantilever components" in the Chinese Technical Specification for Concrete Structures of Tall Buildings.

It is unable for the museum conventional design to satisfy the standard requirements, especially build in high intensity area. Adverse effects of these irregular characteristics on structure seismic performance also have been proved by numerical analysis for conventional structural design. Given the irregularities and complexity of the structure, isolation system is applied to improve seismic behavior of the museum under severe earthquake.

2.3. Isolation System. Compared to several isolation plans, lead rubber bearings and normal rubber bearings are chosen in the museum isolation system to protect superstructures. Total weight of the museum is $1069087 \mathrm{kN}$, and 166 bearings are placed between -2 nd and -1st layer to support it. Details of isolation bearings in prototype structure are shown in Table 3 .

\section{Shaking Table Tests of the Museum Model Structure}

3.1. Shaking Table Facility. The shaking table tests were conducted in the State Key Laboratory for Disaster Reduction in Civil Engineering at Tongji University. The shaking table used in this test has a table dimension of $4 \mathrm{~m}$ by $4 \mathrm{~m}$, and 


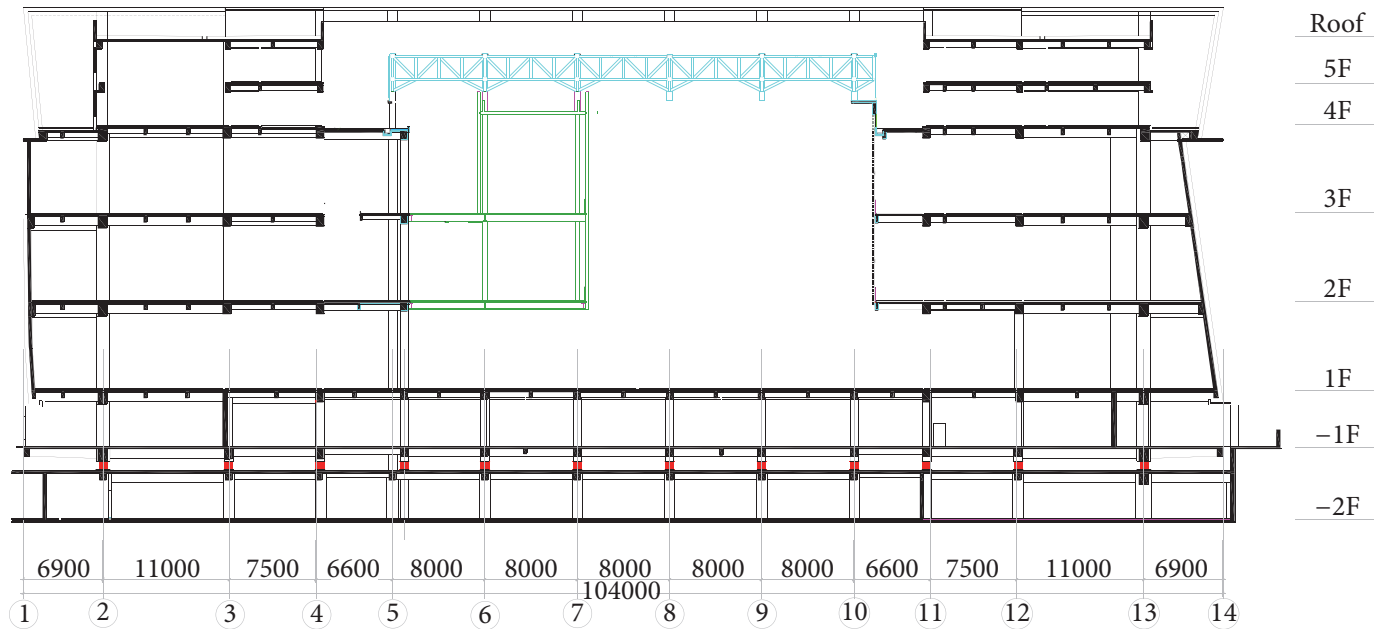

FIGURE 4: Structural profile (unit: $\mathrm{mm}$ ).

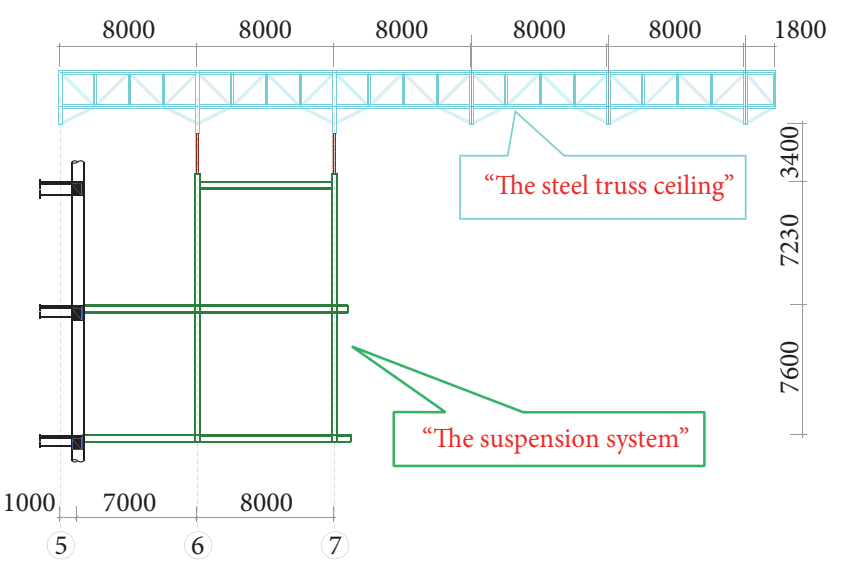

(a)

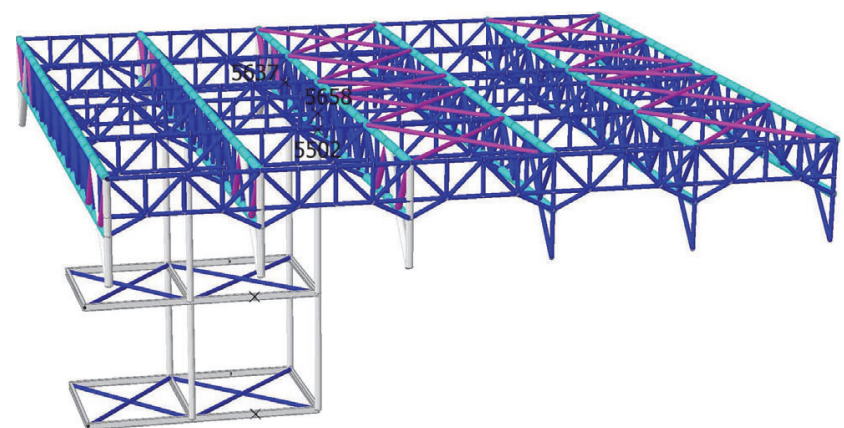

(b)

FIGURE 5: "Treasures fill the house" model (unit: mm): (a) elevation view; (b) 3D model.

TABLE 3: Details and mechanical properties of bearings used in prototype structure.

\begin{tabular}{|c|c|c|c|c|c|c|c|c|}
\hline \multirow{2}{*}{ Bearing } & \multirow{2}{*}{ Number } & \multicolumn{3}{|c|}{ Bearing details } & \multicolumn{4}{|c|}{ Mechanical properties } \\
\hline & & $D(\mathrm{~mm})$ & $T_{r}(\mathrm{~mm})$ & $D_{L}(\mathrm{~mm})$ & $K_{v}(\mathrm{kN} / \mathrm{mm})$ & $K_{d}(\mathrm{kN} / \mathrm{mm})$ & $Q_{d}(\mathrm{kN})$ & $K_{h}(\mathrm{kN} / \mathrm{mm})$ \\
\hline LRB1000 & 93 & 1000 & 190.4 & 200 & 5221 & 1.892 & 252 & 1 \\
\hline LRB800 & 34 & 800 & 185.6 & 160 & 3270 & 1.242 & 161 & 1 \\
\hline RB1000 & 20 & 1000 & 190.4 & l & 4649 & l & / & 4.649 \\
\hline RB800 & 19 & 800 & 185.6 & l & 2885 & / & l & 2.885 \\
\hline
\end{tabular}

Note: $D=$ bearing diameter; $T_{r}=$ total rubber thickness; $D_{L}=$ lead diameter; $K_{v}=$ vertical stiffness; $K_{d}=$ horizontal stiffness; $Q_{d}=$ yielding force; $K_{h}=$ rubber bearing horizontal stiffness.

the maximum payload is $250 \mathrm{kN}$. Its maximum accelerations in longitudinal, transverse, and vertical directions are $1.2 \mathrm{~g}$, $0.8 \mathrm{~g}$, and $0.7 \mathrm{~g}$, respectively. Detailed parameters of this facility are present in [39].

3.2. Model Materials. Test model materials including microaggregate concrete, fine wires, and red copper were used to construct structure model. As shown in Table 4, red copper was used to simulate steel structural members due to its low elastic modulus and similar yielding properties to steel. Microaggregate concrete with fine wires was chosen to construct concrete slabs and RC beam and column members. Fine copper tubes were used to simulate steel braces and steel trusses, and short steel strands were selected to simulate the links of suspension layers and steel trusses. Each suspension layer was fixed on the structural floor. 
TABLE 4: Conversion principles of model materials.

\begin{tabular}{|c|c|c|c|c|c|c|}
\hline $\begin{array}{l}\text { Structural } \\
\text { members }\end{array}$ & Prototyp & icture & Test model & Conversion relations & $\begin{array}{l}\text { Equivalent } \\
\text { principle }\end{array}$ & Note \\
\hline \multirow{3}{*}{ Column/beam } & Section steel & $\begin{array}{l}\text { Flange } \\
\text { Web }\end{array}$ & Red copper & $I^{m}=\alpha \cdot I^{p} \cdot S_{l}^{4}$ & \multirow[t]{2}{*}{ Strength } & $\alpha=1.4$ \\
\hline & Reinfo & bar & Fine wires & $A^{m}=\alpha \cdot A^{p} \cdot S_{l}^{2} \cdot\left(S_{\sigma} / S_{f y}\right)$ & & $\alpha=1.5$ \\
\hline & Concrete $(C$ & $45 / \mathrm{C} 50)$ & Microaggregate concrete & $A^{m}=A^{p} / S_{l}^{2}$ & Area & 1 \\
\hline \multirow{2}{*}{ Floor slab } & Reinfo & bar & Fine wires & $A^{m}=\alpha \cdot A^{p} \cdot S_{l}^{2} \cdot\left(S_{\sigma} / S_{f y}\right)$ & Strength & $\alpha=1.5$ \\
\hline & $\begin{array}{r}\mathrm{Co} \\
(\mathrm{C} 40 / \mathrm{C}\end{array}$ & & Microaggregate concrete & $\begin{array}{c}\text { Prototype: } 100 / 120 / 150 \mathrm{~mm} \\
\text { Test model: } 9 \mathrm{~mm}\end{array}$ & Area & I \\
\hline Steel truss & Circula & tube & Copper tube & $A^{m}=A^{p} / S_{l}^{2}$ & Strength & 1 \\
\hline
\end{tabular}

Note: $A^{m}$ and $A^{p}$ are areas of test model and prototype members, such as column, beam, floor slab, and steel truss.

$I^{m}$ and $I^{p}$ are moments of inertia of test model and prototype members.

$S_{l}, S_{\sigma}$, and $S_{f y}$ are scaling factors of the dimension, design stress, and steel yield strength.

$\alpha$ is a modified coefficient with test model construction errors considered.

TABLE 5: Main similitude relationships.

\begin{tabular}{lc}
\hline Item & Model/prototype \\
\hline Time $S_{t}$ & 0.133 \\
Acceleration $S_{a}$ & 1.888 \\
Velocity $S_{v}$ & 0.251 \\
Displacement $S_{x}$ & $1 / L=1 / 30$ \\
Force $S_{F}$ & $1 / 3600$ \\
Stiffness $S_{k}$ & $1 / 120$ \\
Stress $S_{\sigma}$ & $1 / 4$ \\
Strain $S_{\varepsilon}$ & 1 \\
\hline
\end{tabular}

3.3. Design of Test Structure. According to the dynamic similitude theory, there are three independent controlling scaling factors, and other subordinate scaling factors are derived from them. The purpose of the museum shaking table test is to examine seismic responses of test model with and without isolation bearings, and the use of large scale model in test is the best way to grasp seismic performance of isolated structure. However, it is often practically impossible to conduct testing at full scale and at the proper conditions of loading and history of motion. Given the bearing capacity and the size of the shaking table, the dimension scaling factor $\left(S_{L}\right)$ in the model was chosen to be $1 / 30$, and the model was built with a height of 1.860 . The dimension scaling factor could well meet test code (JG J101-96 Specification of Testing Methods for Earthquake Resistant Building) [40]. The elastic scaling factor $S_{E}$, which was first designed and finally determined according to the test results of material properties, was 0.25 . Thirdly, the acceleration scaling factor $S_{a}$ was set to be 1.888 . All the scaling factors used in the test were derived and are listed in Table 5 [19, 41]. To satisfy similitude relationships, artificial masses (steel plates and concrete blocks) were evenly distributed on the model at each floor, as shown in Figure 7 and Table 6.
Based on general principle of dynamic similarity, isolation period scaling factor $\left(S_{T}\right)$ is

$$
S_{T}=S_{t}=\sqrt{\frac{S_{\sigma} S_{L}}{S_{E}}}
$$

where $S_{T}$ is period scaling factor, $S_{\sigma}$ is stress scaling factor, and $S_{t}$ is time scaling factor. Therefore, the period scale factor $S_{T}$ is determined to be 0.133 (see Table 4), which can meet (1). The velocity scaling factor is [42]

$$
S_{v}=\frac{S_{L}}{S_{t}}
$$

When (1) is substituted in (2), (2) can be rewritten as

$$
S_{v}=\sqrt{\frac{S_{L} S_{E}}{S_{\sigma}}} .
$$

According to the test results of model materials, the elastic scaling factor $S_{E}$ and stress scaling factor $S_{\sigma}$ were both determined to be $1 / 4$. Considering requirements of the same stress-strain curves and $S_{\sigma}=1 / 4$, the strain scaling factor $S_{\varepsilon}$ was set to be 1 [43]. Then, the velocity scaling factor in the model should be 0.251 due to (3).

Theoretically, if $S_{v}=4$ (or $>1$ ) [42] and $S_{L}<1$, lowstrength and high-elastic modulus material will be needed, which is practically impossible to realize. Although yield strength of lead is related to loading cycle, velocity, and temperature, it is hard to satisfy the requirements for velocity scaling factor in practice.

Moreover, due to the small size of the bearings in test, no remarkable reduction of the yield force was observed with the cyclic deformation increases, which should be much more remarkable for large size bearings $[44,45]$.

The base-isolated museum structure with a $4 \mathrm{~m}$ by $4 \mathrm{~m}$ floor plan for shaking table tests is shown in Figures 6 and 7. The overview and structural components of "Treasures fill the house" in model are shown in Figure 8. A rigid base plate 
TABLE 6: Weight of prototype and scale model.

\begin{tabular}{|c|c|c|c|c|}
\hline & & $\begin{array}{c}\text { Dead weight } \\
/ \mathrm{kN}\end{array}$ & $\begin{array}{l}\text { Additional weight } \\
/ \mathrm{kN}\end{array}$ & $\begin{array}{c}\text { Total weight } \\
\text { /kN }\end{array}$ \\
\hline \multirow{10}{*}{ Floor } & "Treasures fill the home" III & 0.20 & 1.19 & 1.39 \\
\hline & "Treasures fill the home" II & - & 0.24 & 0.24 \\
\hline & "Treasures fill the home" I & - & 0.25 & 0.25 \\
\hline & 6 & 1.36 & 11.09 & 12.45 \\
\hline & 5 & 1.12 & 7.41 & 8.53 \\
\hline & 4 & 3.36 & 21.15 & 24.51 \\
\hline & 3 & 3.04 & 19.97 & 23.01 \\
\hline & 2 & 3.57 & 24.45 & 28.02 \\
\hline & 1 & 4.09 & 32.06 & 36.14 \\
\hline & ISO & 64.24 & 0.00 & 64.24 \\
\hline Total weight & & 80.98 & 117.81 & 198.78 \\
\hline
\end{tabular}

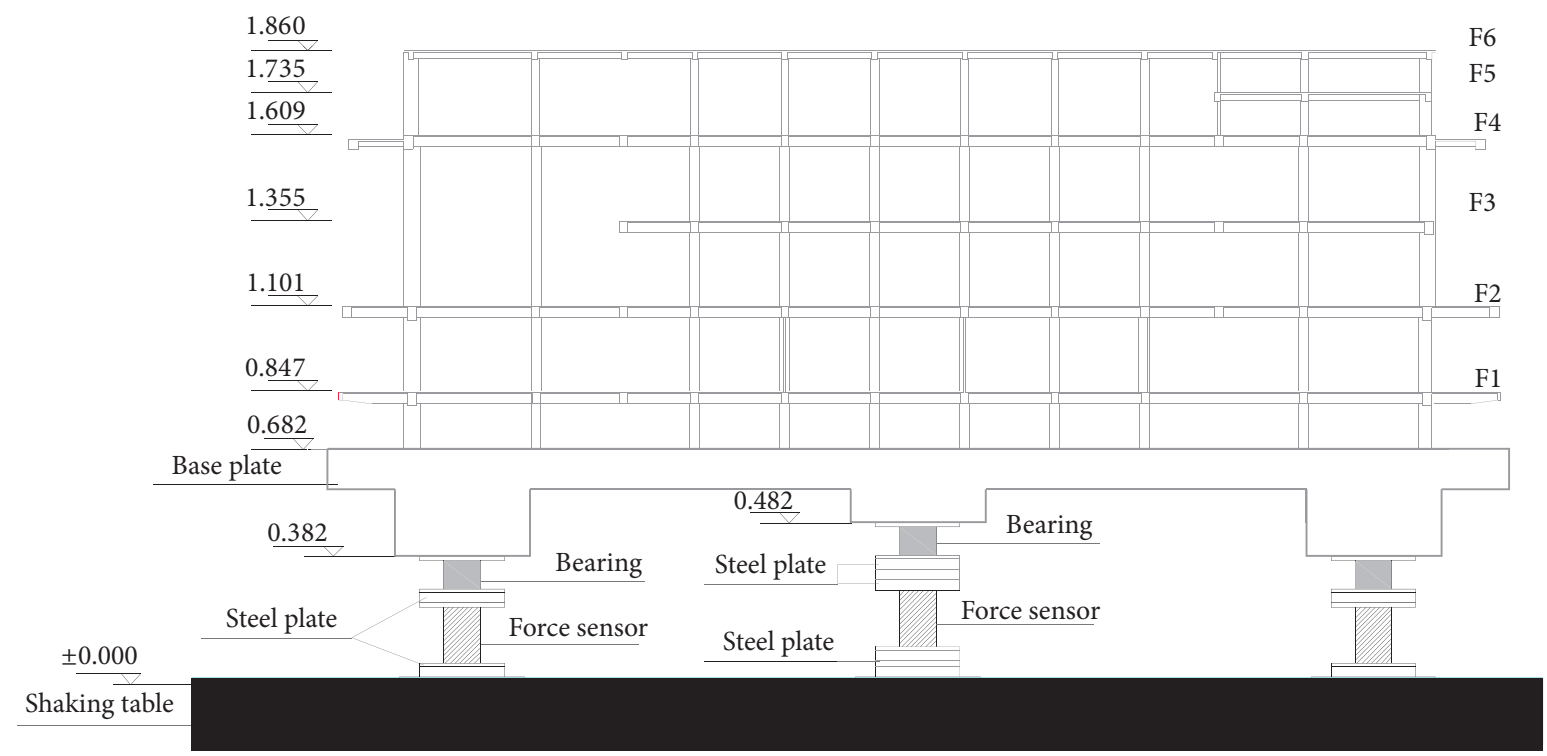

FIGURE 6: Shaking table test model for the isolated structure (unit: $\mathrm{mm}$ ).

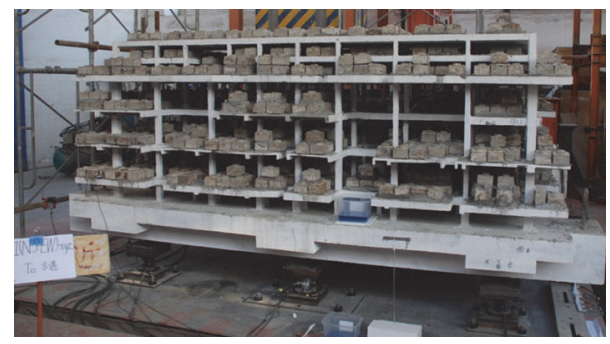

Figure 7: Photograph of shaking table test setup for isolated structure.

was constructed as the basement of the base-fixed structure model, ignoring the interaction of the soil and the prototype structure. The total weight of model is $198.78 \mathrm{kN}$ and details of each layer are shown in Table 2.
The bearings (as shown in Figure 9) used in the isolated model were placed below the base plate, and the period of isolated structure was estimated as $0.542 \mathrm{~s}$ (see Table 8). According to the dimension scale factor, the diameter of scaled bearing in test model should be $33.33 \mathrm{~mm}$ while maximum diameter of prototype bearing is $1000 \mathrm{~mm}$, but this small isolator is unstable and hard to fabricate.

For reasonable bearings used in test model, dynamic similitude of isolation performance was proposed to keep design parameters of isolation layer, such as horizontal stiffness and yielding force, to be consistent with the bearings in prototype model. Considering similitude law, nine lead rubber bearings with $100 \mathrm{~mm}$ diameter were designed in the isolated model, which could well simulate the performance and deformation requirements of the prototype bearings. Major properties of the base isolators are shown in Tables 7 and 8. 
TABLE 7: Fundamental mechanical and material properties of base isolation devices.

\begin{tabular}{lcccccc}
\hline Diameter/mm & $\begin{array}{c}\text { Thickness of } \\
\text { rubber/mm }\end{array}$ & $\begin{array}{c}\text { Primary shape } \\
\text { factor }\end{array}$ & $\begin{array}{c}\text { Secondary shape } \\
\text { factor }\end{array}$ & $\begin{array}{c}\text { Shear } \\
\text { stiffness } / \mathrm{kN}^{\prime} \cdot \mathrm{m}^{-1}\end{array}$ & $\begin{array}{c}\text { Yield } \\
\text { force } / \mathrm{kN}\end{array}$ & $\begin{array}{c}\text { Vertical } \\
\mathrm{modulus} / \mathrm{kN} \cdot \mathrm{m}^{-1}\end{array}$ \\
\hline 100 & 14.3 & 19.23 & 6.99 & 302 & 1.23 & 374200 \\
\hline
\end{tabular}

TABLE 8: Comparison of isolated structure parameters at $100 \%$ shear strain.

\begin{tabular}{|c|c|c|c|c|c|}
\hline Structure & Weight $(\mathrm{kN})$ & $\begin{array}{c}\text { Effective stiffness } \\
(\mathrm{kN} / \mathrm{mm})\end{array}$ & Yield force $(\mathrm{kN})$ & Isolation period (s) & $\begin{array}{l}\text { Yield force } \\
\text { /weight }\end{array}$ \\
\hline Prototype model & 1069087 & 260.38 & 28838.1 & 4.026 & $2.70 \%$ \\
\hline Design model & 199 & 2.713 & 9.65 & 0.538 & $4.95 \%$ \\
\hline Test model & 199 & 2.673 & 7.20 & 0.542 & $3.62 \%$ \\
\hline
\end{tabular}

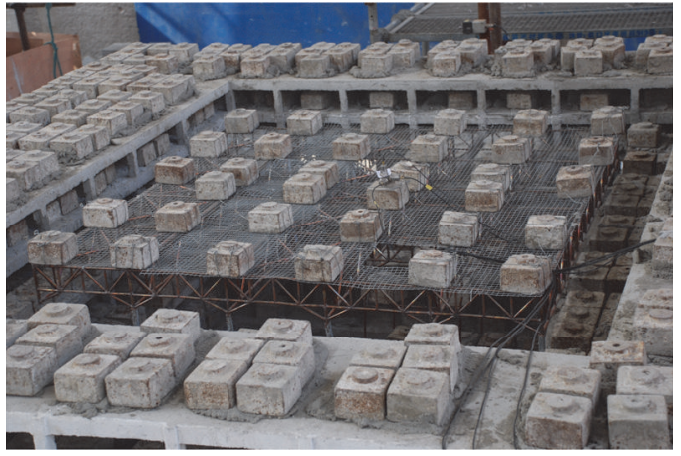

(a)

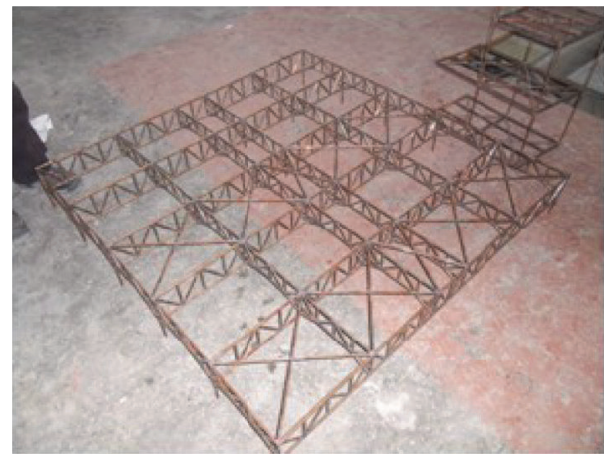

(b)

FIGURE 8: Overview and structural components of "Treasures fill the house": (a) specimen; (b) joints.

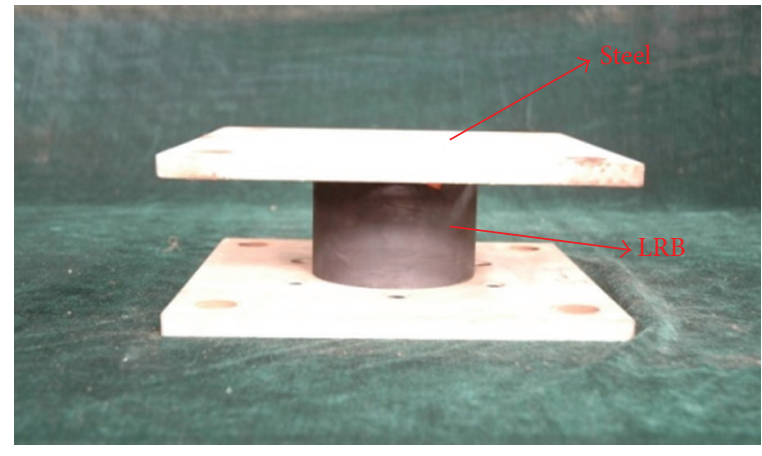

(a)

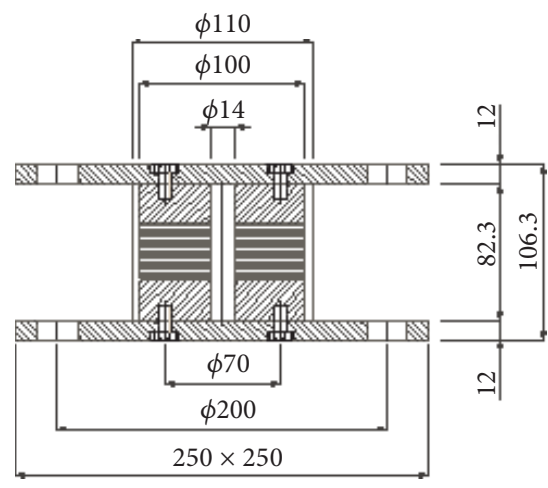

(b)

FIGURE 9: LRB100 bearing used in test: (a) specimen; (b) profile.

3.4. Arrangement of Data Acquisition Points. Three types of sensors, including accelerometers, displacement transducers, and 3-directional force sensors, were installed on the model so that both the global and bearing responses could be measured. Totally, there were 39 piezoelectric acceleration sensors including 23 laboratory shaking table system sensors and 16 external acceleration sensors used to monitor the acceleration responses of test model. The acceleration sensors were located on the shaking table, isolation layer, and each storey of superstructure and steel truss. 15 ASM drawing displacement sensors with ranges of $0 \sim \pm 375 \mathrm{~mm}$ were located on the isolation layer and each storey of superstructure. Seven 3-directional force sensors including three ESM-100 kN type sensors and four YBY type pressure sensors were employed to measure mechanism properties of bearings and analyze horizontal hysteresis performance and vertical force. Distributions of some accelerometers and 3-directional force sensors are shown in Figure 10. 


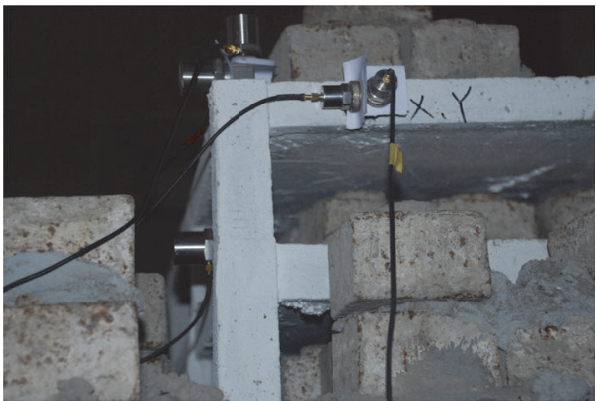

(a)

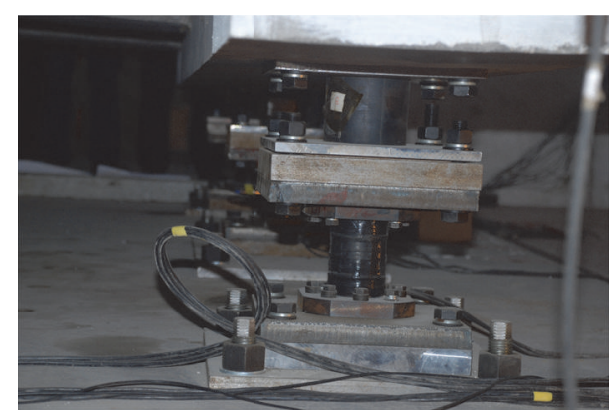

(b)

FIGURE 10: Arrangement diagram of sensors: (a) acceleration sensors; (b) three-directional force sensors.

TABle 9: Parameters of original ground motions selected.

\begin{tabular}{lccccc}
\hline Records & Magnitude & Date & Site class & $\begin{array}{c}\text { Peak acceleration of } \\
\text { original waves/g }\end{array}$ & $\begin{array}{c}\text { Predominate period of response } \\
\text { spectrum/s }\end{array}$ \\
\hline El & 6.7 & 1940.5 .18 & II-III & 0.3417 & 0.55 \\
LWD & 6.7 & 1994.01 .17 & II & 0.207 & 0.120 \\
TJ & 7.6 & 1976.7 .28 & III-IV & $/$ & 1.04 \\
\hline
\end{tabular}

3.5. Test Program. The New Yunnan Provincial Museum was located in the city of Kunming, Yunnan Province. According to the CSDB, the site soil in this city belongs to type III, which is an important factor for selecting earthquake waves in dynamic tests. Considering the definition of type III site soil in the CSDB, the overlaying thickness of the site is no less than $50 \mathrm{~m}$, and average velocity of shear wave in the soil layer is between $150 \mathrm{~m} / \mathrm{s}$ and $250 \mathrm{~m} / \mathrm{s}$. Then three different ground motions (as shown in Table 9) and one artificial wave were selected as input accelerations to the test: (a) the El Centro ground motion (designated as EL) from the California Imperial Valley Earthquake on 18 May 1940, which has been extensively used in Chinese design practice for the major level; (b) LWD-DEL AMO ground motion (designated as LWD) obtained from the 1994 Northridge Earthquake in USA; (c) Tianjin ground motion (designated as TJ) obtained from 1974 Tangshan Earthquake in China; (d) the Kunming artificial wave (ART). As shown in Figure 11, the ART wave fits the design spectra well and the other three earthquake waves decrease remarkably in the long period section, while the structural period of isolated prototype museum is $4.026 \mathrm{~s}$. Considering the adverse effect of long period earthquake waves to isolated structure, the ART wave is used to verify isolation effectiveness and ensure the safety of isolated museum structure.

Details of the waves attacked the test model in the tests are also important parameters for shaking table tests. Figure 12 shows the time histories and the corresponding Fourier amplitude spectra of the four scaled input motions measured from the shaking table. As shown in Figure 12, the predominant frequencies of scaled waves are 15.66, 18.75, 5.61 , and $14.86 \mathrm{~Hz}$. For the dominant period of isolated test model is $0.542 \mathrm{~s}$, much more components of the ART wave close to this period could be seen in Figure 12 and greater

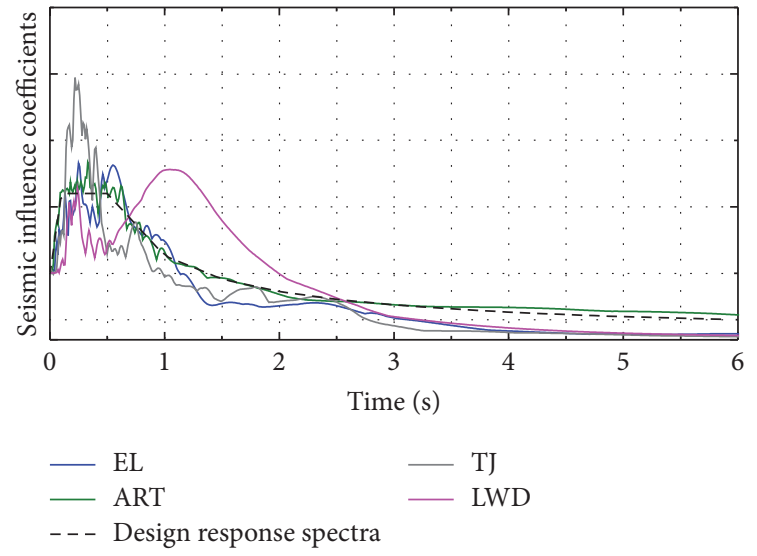

FIGURE 11: Acceleration response spectrums of four waves used in test and the design response spectra specified in the CSDB.

seismic responses were achieved accordingly in the following test results of isolated model with the ART wave input.

According to the CSDB, three earthquake input levels, including minor, moderate, and major earthquakes, should be considered in shaking table tests. As Kunming belongs to the seismic zone of intensity 8 , the peak ground accelerations (PGAs) for isolated structure design corresponding to the three different levels are specified as $0.132 \mathrm{~g}, 0.378 \mathrm{~g}$, and $0.755 \mathrm{~g}$, respectively. In the seismic response analysis for the prototype structure with and without isolation, seismic-reduced factor (max ratio of structures storey shear forces with and without isolation) is less than 0.4 , and the superstructure supported by isolation bearings could be 

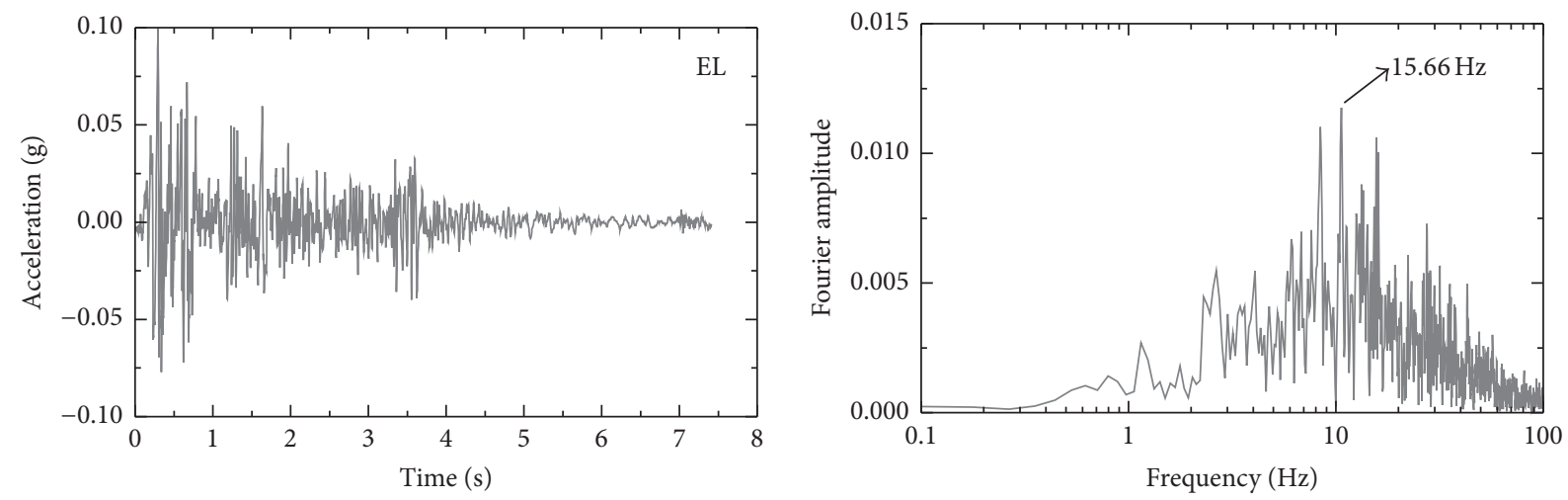

(a) EL wave
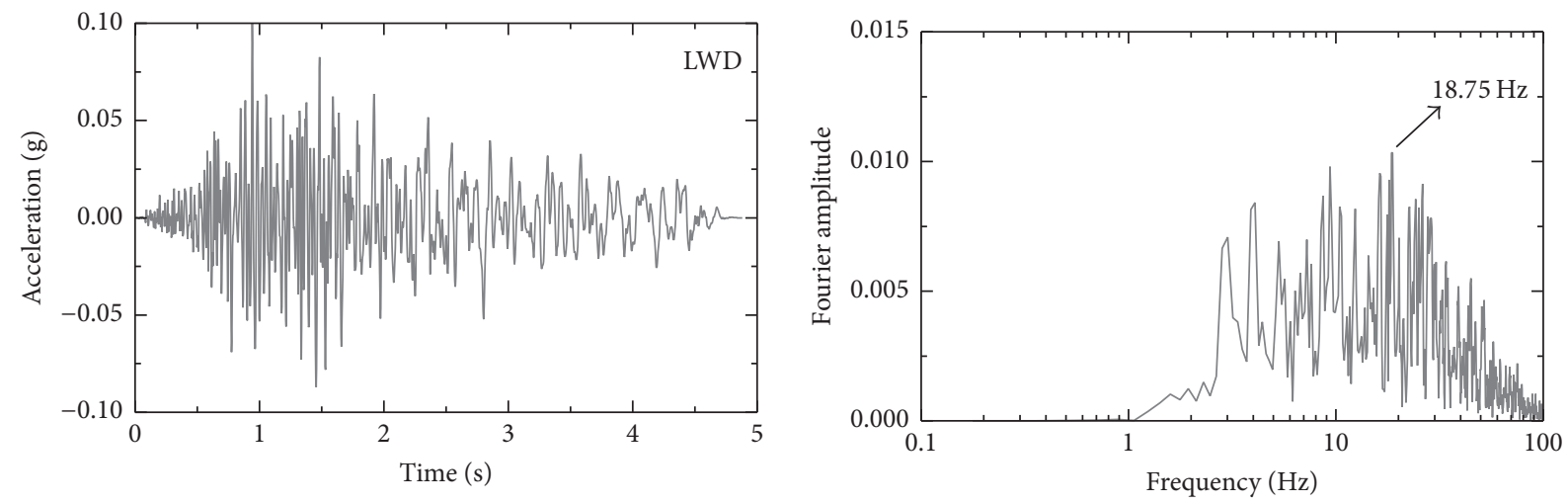

(b) LWD wave
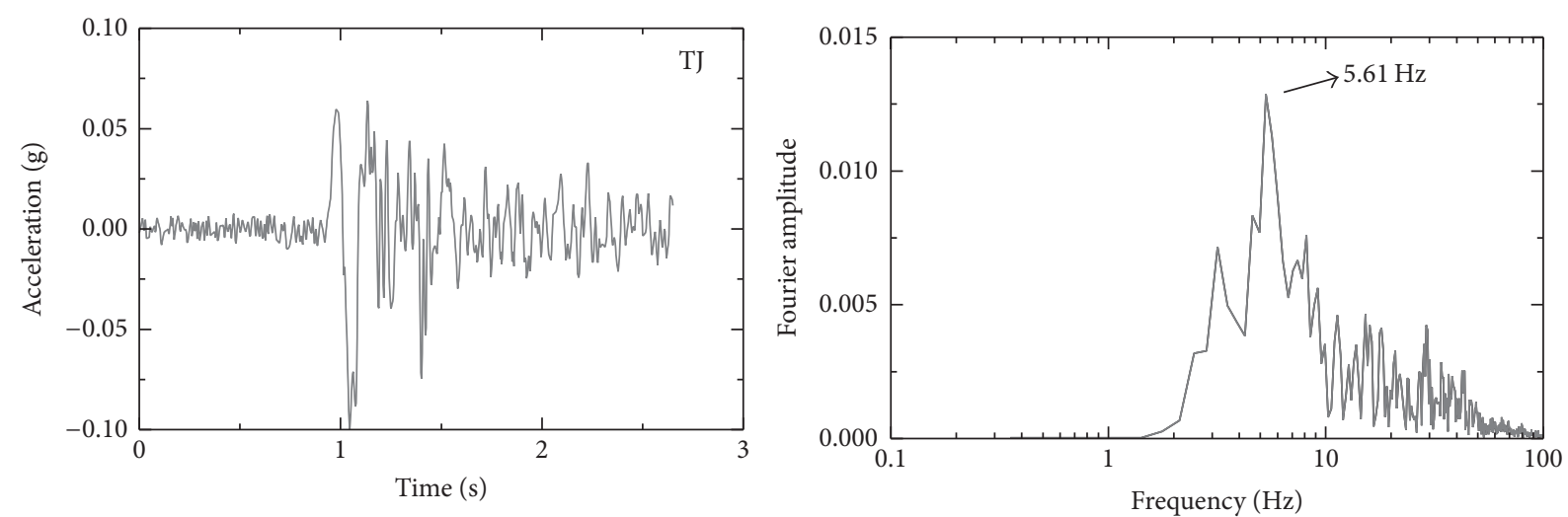

(c) $\mathrm{TJ}$ wave
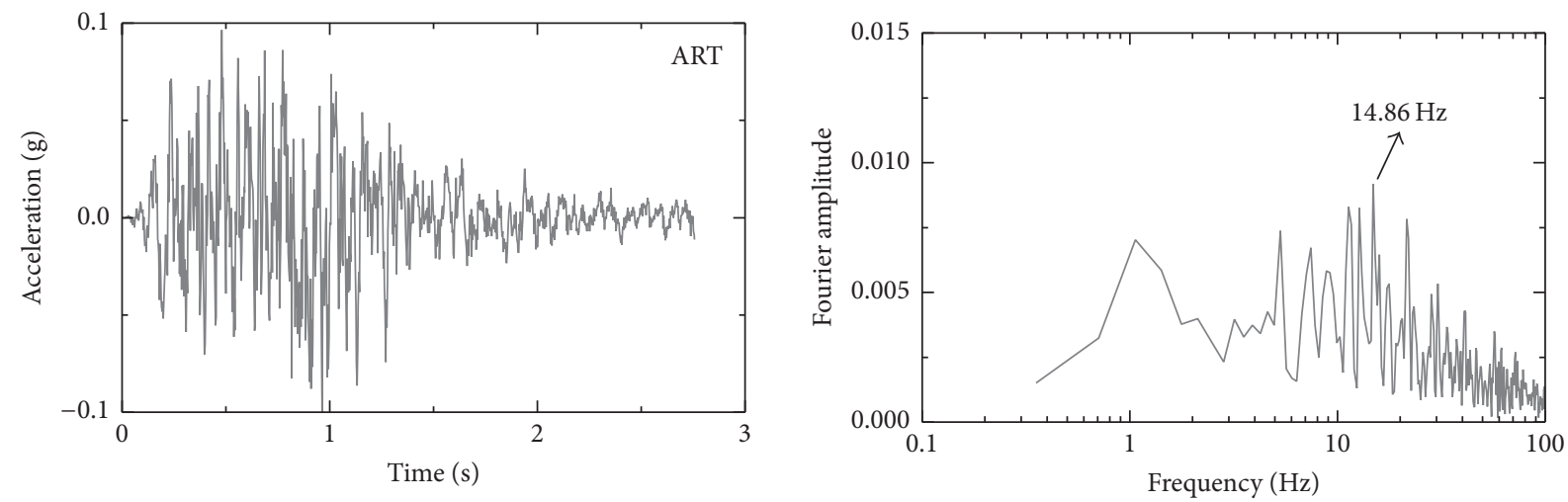

(d) ART wave

FIGURE 12: Time histories and Fourier amplitude spectra of input ground motion acceleration from shaking table surface. 
TABLE 10: Test program for the isolated structure.

\begin{tabular}{|c|c|c|c|c|c|}
\hline \multirow{2}{*}{ Test case } & \multirow{2}{*}{ Input signal } & \multicolumn{3}{|c|}{ Peak value of input acceleration(g) } & \multirow{2}{*}{ Note } \\
\hline & & $x$ & $y$ & $z$ & \\
\hline 1 & White noise & 0.1 & 0.1 & 0.1 & - \\
\hline 2 & $\mathrm{EL}(\mathrm{NS})-x$ & 0.132 & & & Minor 8 \\
\hline 3 & $\operatorname{LWD}(\mathrm{EW})-x$ & 0.132 & & & Minor 8 \\
\hline 4 & $\mathrm{TJ}(\mathrm{EW})-x$ & 0.132 & & & Minor 8 \\
\hline 5 & ART- $x$ & 0.132 & & & Minor 8 \\
\hline 6 & $\mathrm{EL}(\mathrm{NS})-y$ & & 0.132 & & Minor 8 \\
\hline 7 & LWD(EW)- $y$ & & 0.132 & & Minor 8 \\
\hline 8 & $\mathrm{TJ}(\mathrm{EW})-y$ & & 0.132 & & Minor 8 \\
\hline 9 & ART- $y$ & & 0.132 & & Minor 8 \\
\hline 10 & $\mathrm{EL}-x y z$ & 0.132 & 0.112 & 0.086 & Minor 8 \\
\hline 11 & LWD- $x y z$ & 0.132 & 0.112 & 0.086 & Minor 8 \\
\hline 12 & TJ-xyz & 0.132 & 0.112 & 0.086 & Minor 8 \\
\hline 13 & White noise & 0.1 & 0.1 & 0.1 & - \\
\hline 14 & $\mathrm{EL}(\mathrm{NS})-x$ & 0.378 & & & Moderate 8 \\
\hline 15 & LWD(EW)- $x$ & 0.378 & & & Moderate 8 \\
\hline 16 & TJ(EW)-x & 0.378 & & & Moderate 8 \\
\hline 17 & ART- $x$ & 0.378 & & & Moderate 8 \\
\hline 18 & $\mathrm{EL}(\mathrm{NS})-y$ & & 0.378 & & Moderate 8 \\
\hline 19 & LWD(EW)- $y$ & & 0.378 & & Moderate 8 \\
\hline 20 & TJ(EW)-y & & 0.378 & & Moderate 8 \\
\hline 21 & ART- $y$ & & 0.378 & & Moderate 8 \\
\hline 22 & EL- $x y z$ & 0.378 & 0.321 & 0.245 & Moderate 8 \\
\hline 23 & LWD- $x y z$ & 0.378 & 0.321 & 0.245 & Moderate 8 \\
\hline 24 & TJ-xyz & 0.378 & 0.321 & 0.245 & Moderate 8 \\
\hline 25 & White noise & 0.1 & 0.1 & 0.1 & - \\
\hline 26 & $\mathrm{El}(\mathrm{NS})-x$ & 0.755 & & & Major 8 \\
\hline 27 & LWD(EW)-x & 0.755 & & & Major 8 \\
\hline 28 & TJ(EW)-x & 0.755 & & & Major 8 \\
\hline 29 & ART- $x$ & 0.755 & & & Major 8 \\
\hline 30 & $\mathrm{El}(\mathrm{NS})-y$ & & 0.755 & & Major 8 \\
\hline 31 & $\operatorname{LWD}(\mathrm{EW})-y$ & & 0.755 & & Major 8 \\
\hline 32 & TJ(EW)-y & & 0.755 & & Major 8 \\
\hline 33 & ART- $y$ & & 0.755 & & Major 8 \\
\hline 34 & El-xyz & 0.755 & 0.642 & 0.491 & Major 8 \\
\hline 35 & LWD-xyz & 0.755 & 0.642 & 0.491 & Major 8 \\
\hline 36 & TJ-xyz & 0.755 & 0.642 & 0.491 & Major 8 \\
\hline 37 & White noise & 0.05 & 0.05 & 0.05 & - \\
\hline
\end{tabular}

designed as intensity 7 due to the CSDB. The peak ground accelerations (PGAs) for superstructure corresponding to the three input levels are specified as $0.092 \mathrm{~g}, 0.264 \mathrm{~g}$, and $0.581 \mathrm{~g}$, respectively. There were unidirectional and threedimensional inputs used in the shaking table tests. As stipulated for three-dimensional inputs by CSDB, the PGA ratio of the principal direction to the other direction should be $1: 0.85: 0.65$.

The objective of the white noise excitation tests is to measure the dynamic properties of the model structure and investigate the variations of dynamic characteristics of model structures with and without isolation. A total of 74 cases were conducted in test, and a summary of the inputs used for each case is presented in Tables 10 and 11.

\section{Shaking Table Test Results}

4.1. Dynamic Properties of Model Structure. Before and after each test phase, as mentioned in Section 3.5, white noise signal was input to the model structure and its dynamic performance information was recorded by sensors. Comparisons of initial natural frequency values measured in 
TABLE 11: Test program for the base-fixed structure.

\begin{tabular}{|c|c|c|c|c|c|}
\hline \multirow{2}{*}{ Test case } & \multirow{2}{*}{ Input signal } & \multicolumn{3}{|c|}{ Peak value of input acceleration(g) } & \multirow{2}{*}{ Note } \\
\hline & & $x$ & $y$ & $z$ & \\
\hline 1 & White noise & 0.05 & 0.05 & 0.05 & - \\
\hline 2 & $\mathrm{El}(\mathrm{NS})-x$ & 0.092 & & & Minor 7 \\
\hline 3 & $\operatorname{LWD}(\mathrm{EW})-x$ & 0.092 & & & Minor 7 \\
\hline 4 & $\mathrm{TJ}(\mathrm{EW})-x$ & 0.092 & & & Minor 7 \\
\hline 5 & ART- $x$ & 0.092 & & & Minor 7 \\
\hline 6 & $\mathrm{El}(\mathrm{NS})-y$ & & 0.092 & & Minor 7 \\
\hline 7 & $\operatorname{LWD}(\mathrm{EW})-y$ & & 0.092 & & Minor 7 \\
\hline 8 & TJ(EW)-y & & 0.092 & & Minor 7 \\
\hline 9 & ART- $y$ & & 0.092 & & Minor 7 \\
\hline 10 & El-xyz & 0.092 & 0.078 & 0.060 & Minor 7 \\
\hline 11 & LWD- $x y z$ & 0.092 & 0.078 & 0.060 & Minor 7 \\
\hline 12 & TJ-xyz & 0.092 & 0.078 & 0.060 & Minor 7 \\
\hline 13 & White noise & 0.05 & 0.05 & 0.05 & - \\
\hline 14 & EL(NS)- $x$ & 0.264 & & & Moderate 7 \\
\hline 15 & $\operatorname{LWD}(\mathrm{EW})-x$ & 0.264 & & & Moderate 7 \\
\hline 16 & TJ(EW)-x & 0.264 & & & Moderate 7 \\
\hline 17 & ART- $x$ & 0.264 & & & Moderate 7 \\
\hline 18 & $\mathrm{EL}(\mathrm{NS})-y$ & & 0.264 & & Moderate 7 \\
\hline 19 & $\operatorname{LWD}(\mathrm{EW})-y$ & & 0.264 & & Moderate 7 \\
\hline 20 & TJ(EW)-y & & 0.264 & & Moderate 7 \\
\hline 21 & ART- $y$ & & 0.264 & & Moderate 7 \\
\hline 22 & EL-xyz & 0.264 & 0.224 & 0.171 & Moderate 7 \\
\hline 23 & LWD-xyz & 0.264 & 0.224 & 0.171 & Moderate 7 \\
\hline 24 & $\mathrm{TJ}-x y z$ & 0.264 & 0.224 & 0.171 & Moderate 7 \\
\hline 25 & White noise & 0.05 & 0.05 & 0.05 & - \\
\hline 26 & EL(NS)- $x$ & 0.581 & & & Major 7 \\
\hline 27 & $\operatorname{LWD}(\mathrm{EW})-x$ & 0.581 & & & Major 7 \\
\hline 28 & TJ(EW)- $x$ & 0.581 & & & Major 7 \\
\hline 29 & ART- $x$ & 0.581 & & & Major 7 \\
\hline 30 & EL(NS)- $y$ & & 0.581 & & Major 7 \\
\hline 31 & LWD(EW)-y & & 0.581 & & Major 7 \\
\hline 32 & $\mathrm{TJ}(\mathrm{EW})-y$ & & 0.581 & & Major 7 \\
\hline 33 & ART- $y$ & & 0.581 & & Major 7 \\
\hline 34 & $\mathrm{EL}-x y z$ & 0.581 & 0.494 & 0.378 & Major 7 \\
\hline 35 & LWD-xyz & 0.581 & 0.494 & 0.378 & Major 7 \\
\hline 36 & $\mathrm{TJ}-x y z$ & 0.581 & 0.494 & 0.378 & Major 7 \\
\hline 37 & White noise & 0.05 & 0.05 & 0.05 & - \\
\hline
\end{tabular}

white noise cases for the isolated structure and base-fixed structure are presented in Table 12. The first two modes of the isolated structure are of translation in directions $x$ and $y$ with the same initial natural periods of $0.257 \mathrm{~s}$. The third mode is of torsion with an initial natural period of $0.235 \mathrm{~s}$. For fixed model, the first three vibration modes frequencies are $0.118 \mathrm{~s}, 0.101 \mathrm{~s}$, and $0.091 \mathrm{~s}$, the same as isolated model of translation in directions $x$ and $y$ and the torsional mode.

The variations of average frequency (variation of frequency $=$ (frequency after shaking table tests original frequency)/original frequency) values for each mode have been also listed in Table 12. The average variation values for the isolated structure are $0 \%,-1.0 \%$, and $-1.2 \%$ after the minor, moderate, and major level earthquake inputs, which indicates that the isolated model definitely remains in elastic without any damage under minor earthquake and with a little damage under moderate and major level. This is also consistent with the ordinary assumption of elastic state under minor earthquakes.

For the fixed model, the average variation values are $-3.4 \%,-7.60 \%$, and $-20.60 \%$ after the minor, moderate, and major level earthquake inputs. Although the natural frequency of base-fixed structure decreased a little after 
TABLE 12: Dynamic characteristics test results of isolated structure model.

\begin{tabular}{|c|c|c|c|c|c|c|c|c|c|c|}
\hline Mode & Description & 1 & 2 & 3 & 4 & 5 & 6 & 7 & 8 & AVE \\
\hline \multirow{7}{*}{ Isolated structure model } & Initial $(\mathrm{Hz})$ & 3.89 & 3.89 & 4.25 & 19.11 & 21.94 & 42.81 & 57.32 & 69.00 & \\
\hline & Minor $8(\mathrm{~Hz})$ & 3.89 & 3.89 & 4.25 & 19.11 & 21.94 & 42.81 & 57.32 & 69.00 & \\
\hline & Variation (\%) & 0.00 & 0.00 & 0.00 & 0.00 & 0.00 & 0.00 & 0.00 & 0.00 & 0.00 \\
\hline & Moderate $8(\mathrm{~Hz})$ & 3.89 & 3.89 & 4.25 & 18.40 & 21.05 & 42.81 & 57.32 & 68.64 & \\
\hline & Variation (\%) & 0.00 & 0.00 & 0.00 & -3.70 & -4.10 & 0.00 & 0.00 & -0.50 & -1.00 \\
\hline & Major $8(\mathrm{~Hz})$ & 3.89 & 3.89 & 4.25 & 18.40 & 21.05 & 42.28 & 57.32 & 68.64 & \\
\hline & Variation (\%) & 0.00 & 0.00 & 0.00 & -3.70 & -4.10 & -1.20 & 0.00 & -0.50 & -1.20 \\
\hline \multirow{7}{*}{ Base-fixed structure model } & Initial (Hz) & 8.49 & 9.91 & 10.97 & 14.86 & 15.21 & 47.06 & 33.79 & 39.81 & \\
\hline & Minor $8(\mathrm{~Hz})$ & 8.14 & 9.55 & 10.97 & 14.15 & 14.51 & 46.23 & 31.84 & 38.92 & \\
\hline & Variation (\%) & -4.20 & -3.60 & 0.00 & -4.80 & -4.60 & -1.80 & -5.80 & -2.20 & -3.40 \\
\hline & Moderate $8(\mathrm{~Hz})$ & 7.07 & 9.20 & 10.26 & 13.8 & 14.51 & 45.29 & 30.78 & 37.51 & \\
\hline & Variation (\%) & -16.70 & -7.10 & -6.50 & -7.10 & -4.60 & -3.80 & -8.90 & -5.80 & -7.60 \\
\hline & Major $8(\mathrm{~Hz})$ & 6.02 & 7.08 & 8.49 & 11.68 & 12.03 & 42.64 & 27.95 & 33.61 & \\
\hline & Variation (\%) & -29.20 & -28.60 & -22.60 & -21.40 & -20.90 & -9.40 & -17.30 & -15.60 & -20.60 \\
\hline
\end{tabular}

minor earthquake, it was still much more than that of the isolated structure under moderate and major earthquake. The base-fixed structure has even more serious damage than the isolated structure after major earthquake. Besides, the first torsion frequency of the isolated structure is $4.25 \mathrm{~Hz}$ after different levels earthquake input. However, the values for the base-fixed structure are $10.97 \mathrm{~Hz}, 10.26 \mathrm{~Hz}$, and $7.08 \mathrm{~Hz}$ after minor 7 , moderate 7 , and major 7 tests, implying that serve damage has taken place in the model due to the reduction of torsion stiffness.

4.2. Structural Acceleration Responses. Acceleration responses were measured directly by mounted accelerometers on the model. The acceleration amplification factor (AAF) which is usually defined as the ratio of the peak value of floor accelerations response to the PGA of input waves is used to evaluate acceleration vibration amplification effects at different floor of the New Yunnan Provincial Museum structure with and without isolation bearings.

The profiles of acceleration amplification factor (AAF) for the isolated model (ISO) and fixed model (FIX) are shown in Figures 13, 14, and 15, where the AAF envelop values of each case are used. Compared with the fixed structure, the maximum AAFs for the isolated structure under three level ground motions are all less than 1 for both horizontal dimensions, implying the effectiveness of the isolation system. For the vertical response, it is clear that the acceleration differences of isolated and fixed models are little with minor earthquake input and becoming increasingly significant with earthquake loads arise.

The storey distributions for the isolated structure are close to a linear characteristic, and whip effects have been effectively controlled. With arising of seismic inputs, the decreases of superstructure acceleration responses are increasingly obvious. Figures 16 and 17 show the acceleration time histories of roof and the corresponding Fourier amplitude spectra of the isolated structure (ISO) and fixed structure (FIX) under major earthquakes. It is clearly shown in Figure 17 that isolation bearings filter out vast vibrations of building structure in the wide short period regions and only amplify few vibrations in the specified long period regions because of filtering effect. The results can explain the reduction effect of absolute acceleration of base-isolated structure.

For architectural aesthetics and large exhibition space of the museum, the "Treasures fill the house" system composed of steel trusses and suspension layers hanging below was designed in the atrium. As an additional system of the whole structure, it arises construction clearance and reduces crosssection of steel beam at same time.

For structural design, it is essential to analyze the seismic responses of this suspension system because of its weakening in lateral stiffness. The distributions of "Treasures fill the house" AAFs under the three level earthquakes are presented in Figures 18, 19, and 20. As shown, the maximum AAF values for the base-fixed structure are almost 12 times of those for isolated structure, and obvious isolation effects for the "Treasures fill the house" could be achieved. It is clear that AAFs in the $x$ direction are much larger than that in $y$ direction due to difference of lateral stiffness for base-fixed structure, and the variations are much smaller of isolated structure. With increasing of input earthquake level, AAF differences between isolated and fixed structures vary little for each horizontal direction. In general, the acceleration responses could be reduced by about $80 \%$ and $78 \%$ in directions $x$ and $y$, respectively. For vertical direction, no obvious differences of two models could be achieved with minor earthquake input, and AAFs of isolated model are much less than that of fixed structure under moderate and major earthquake. The acceleration responses of the steel truss and the suspension layer could be effectively reduced by isolation bearings.

4.3. Displacement Responses. The max displacement responses of isolated model with different intensity earth- 


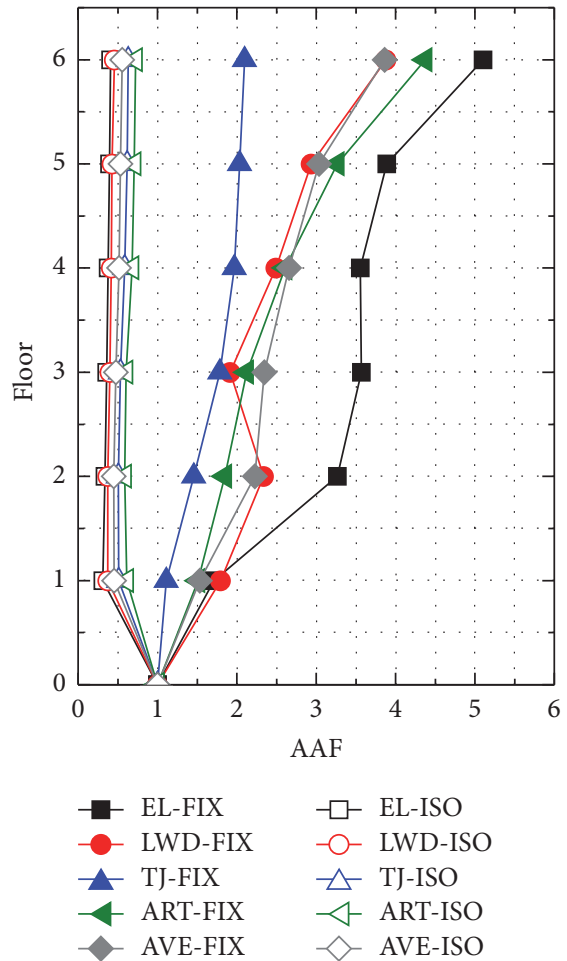

(a)
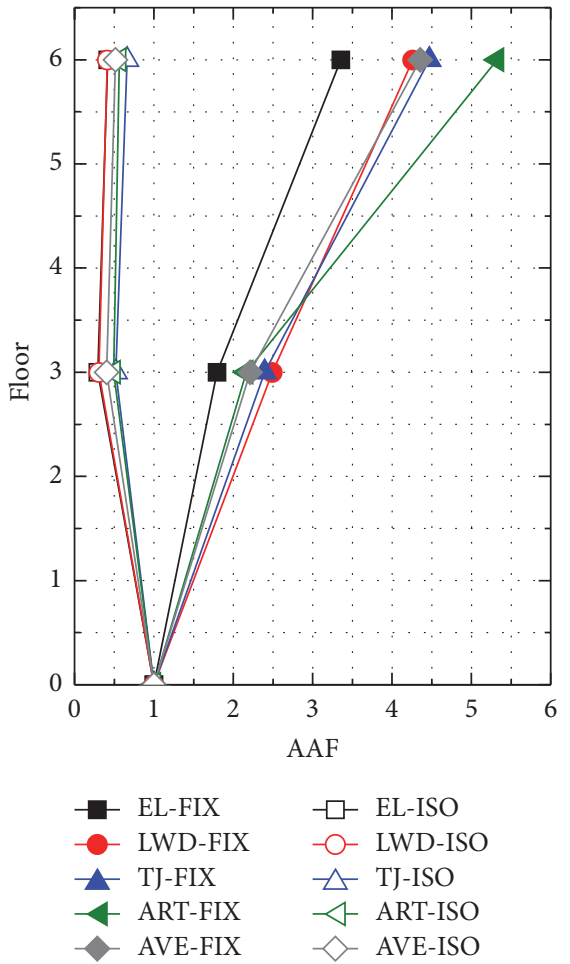

(b)
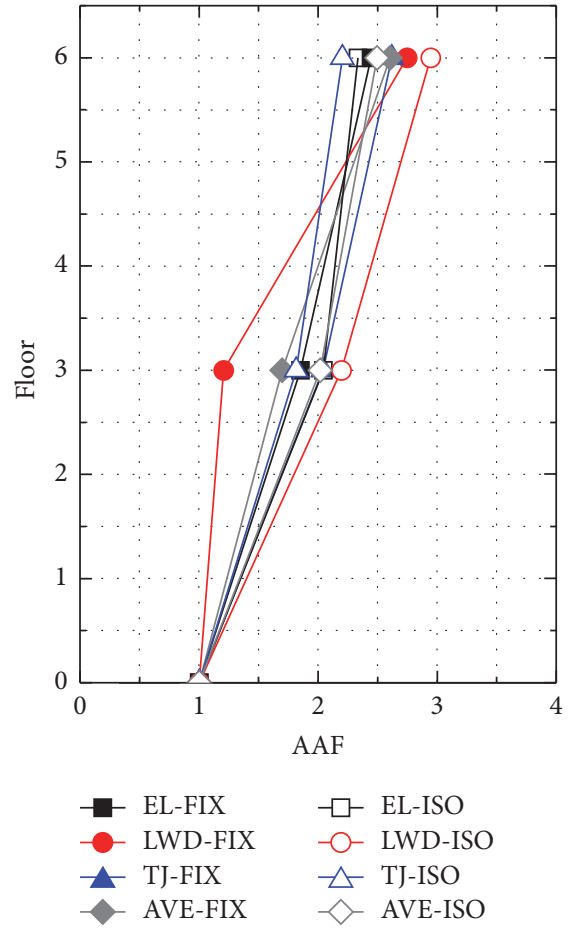

(c)

FIGURE 13: Comparisons of AAF for the isolated and fixed structures under minor earthquakes: (a) direction $x$; (b) direction $y$; and (c) direction $z$.
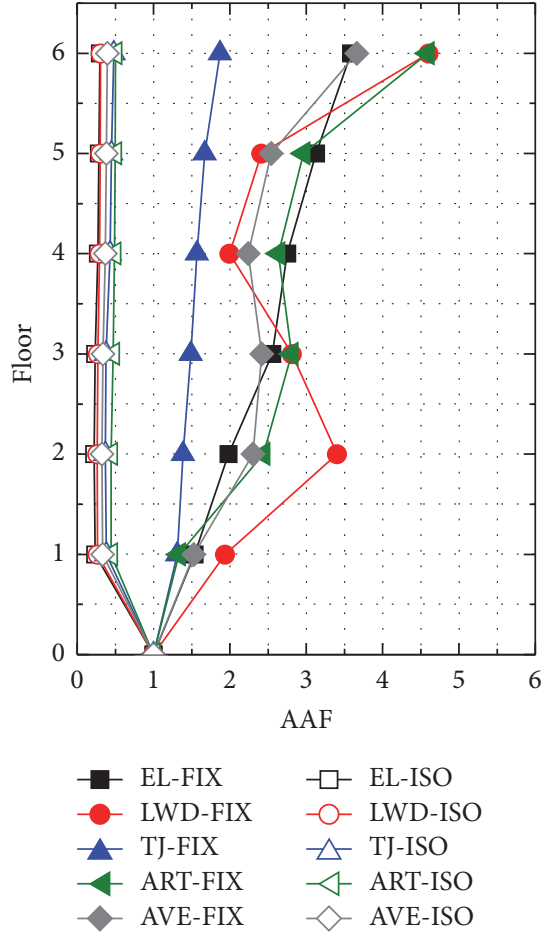

(a)
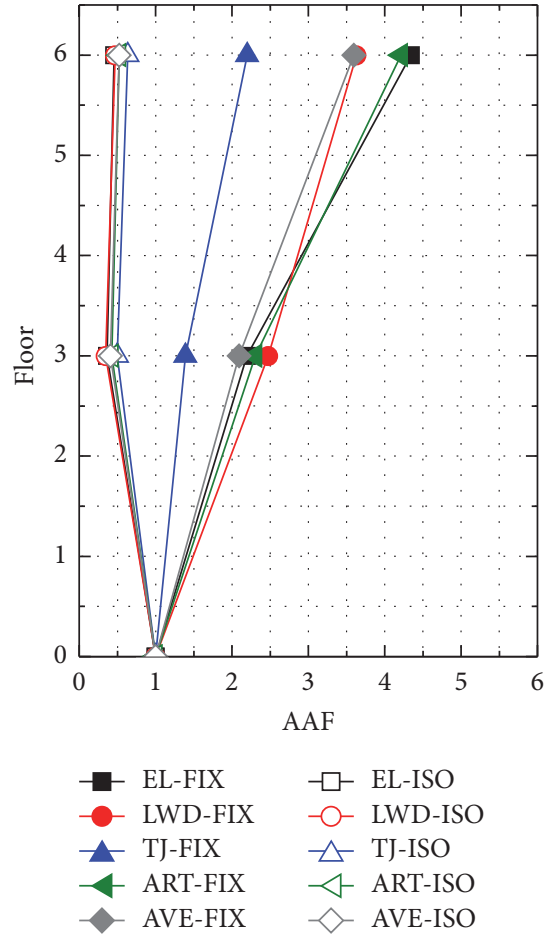

(b)
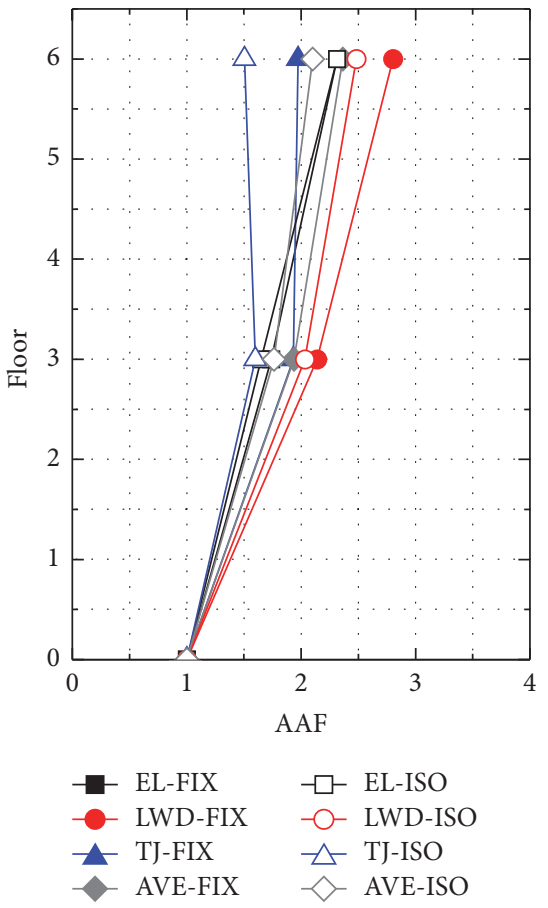

(c)

FIGURE 14: Comparisons of AAF for the isolated and fixed structures under moderate earthquakes: (a) direction $x$; (b) direction $y$; and (c) direction $z$. 

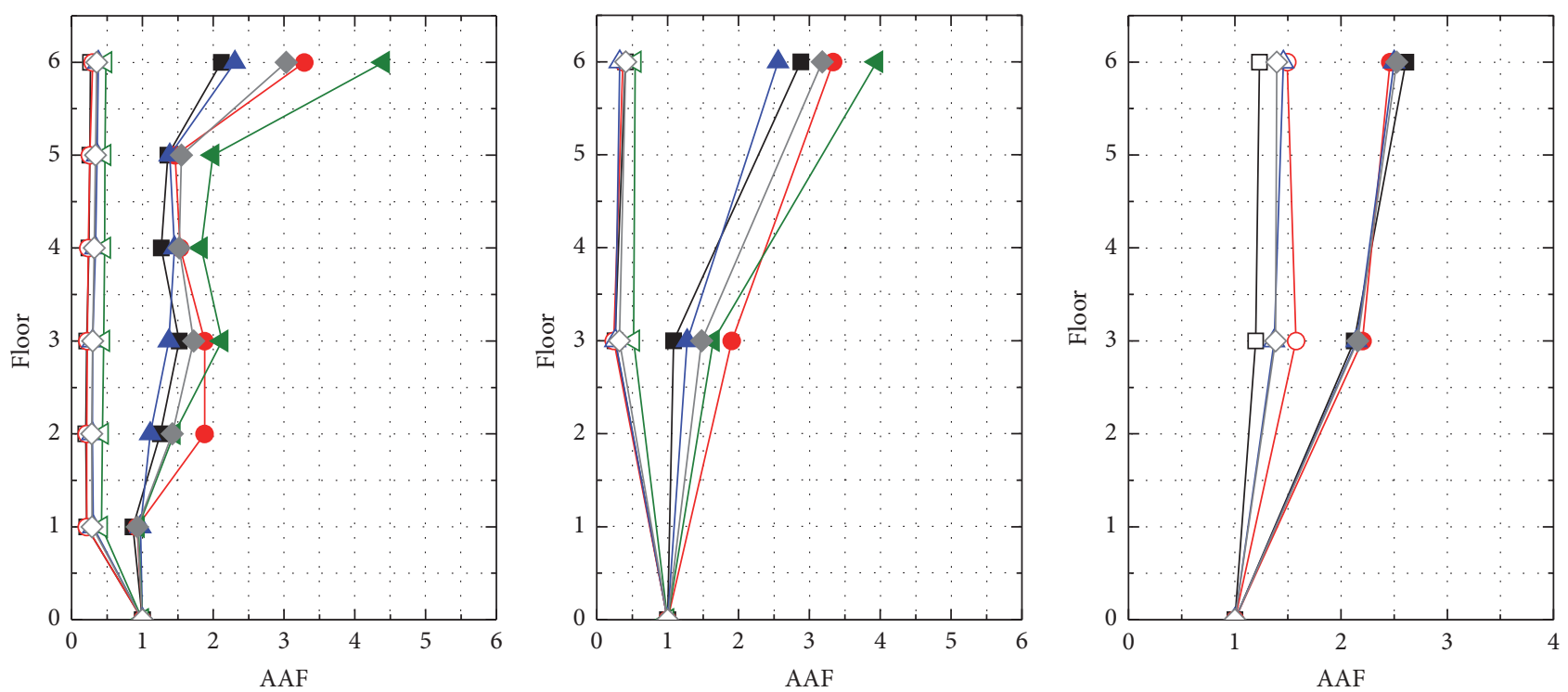

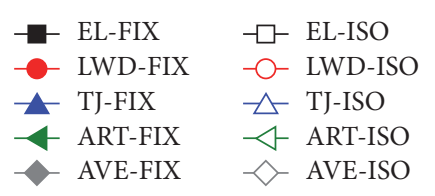

(a)

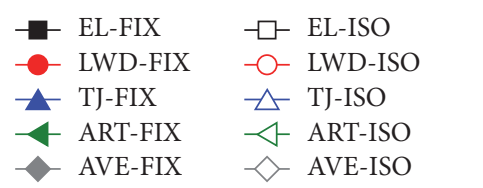

(b)

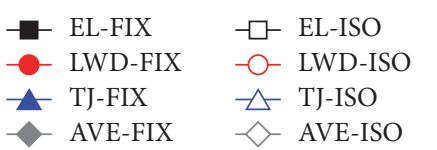

(c)

FIGURE 15: Comparisons of AAF for the isolated and fixed structures under major earthquakes: (a) direction $x$; (b) direction $y$; and (c) direction $z$.
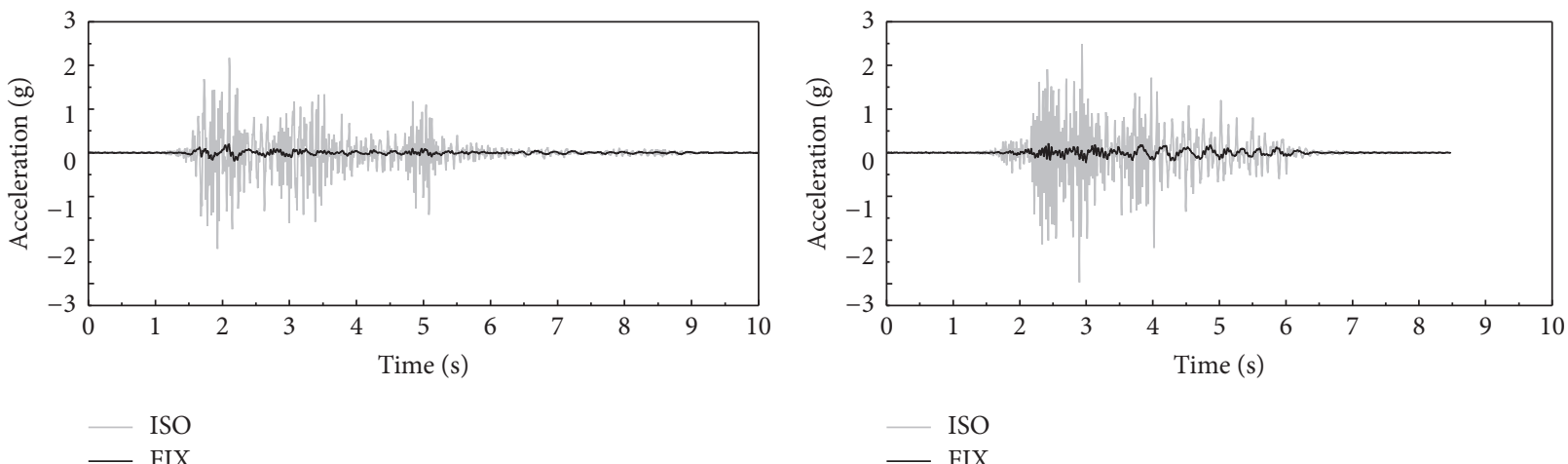

(a) EL

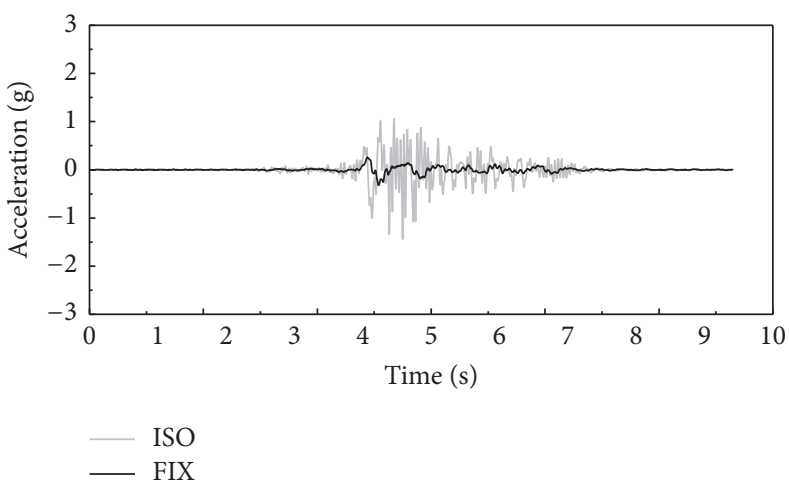

(c) $\mathrm{TJ}$

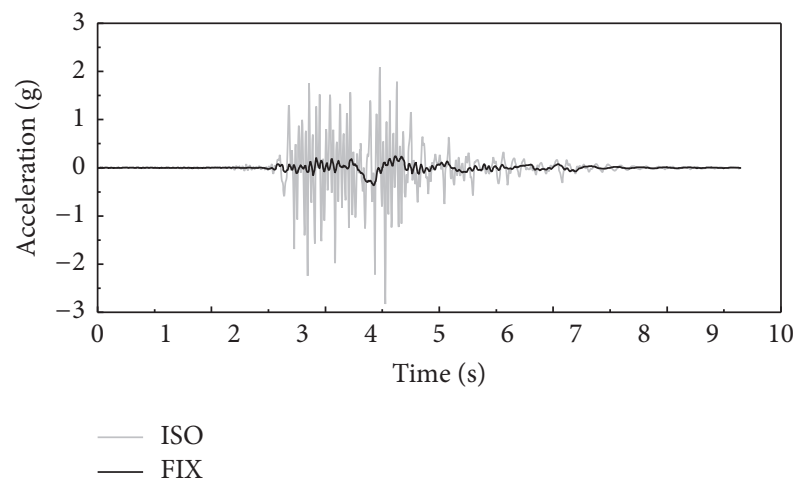

(d) ART

FIGURE 16: Comparisons on roof acceleration time history of the isolated and fixed structure under major earthquake in direction $x$. 


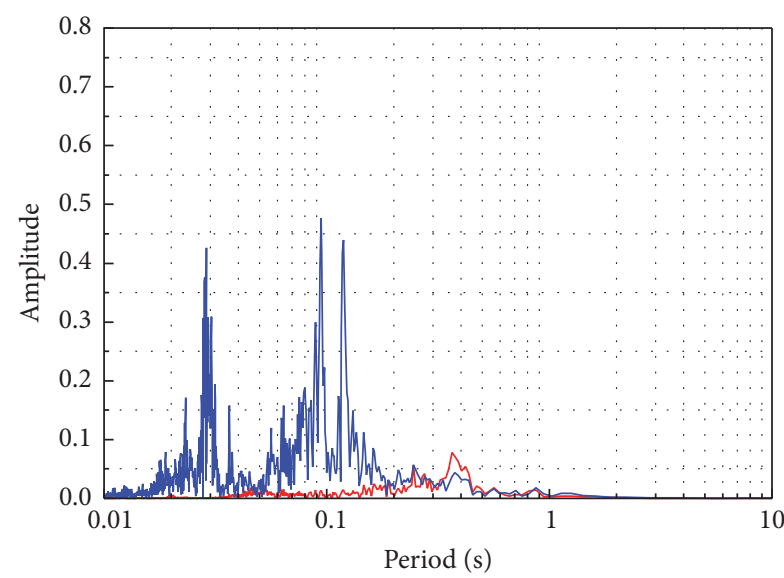

- ISO

- FIX

(a) EL

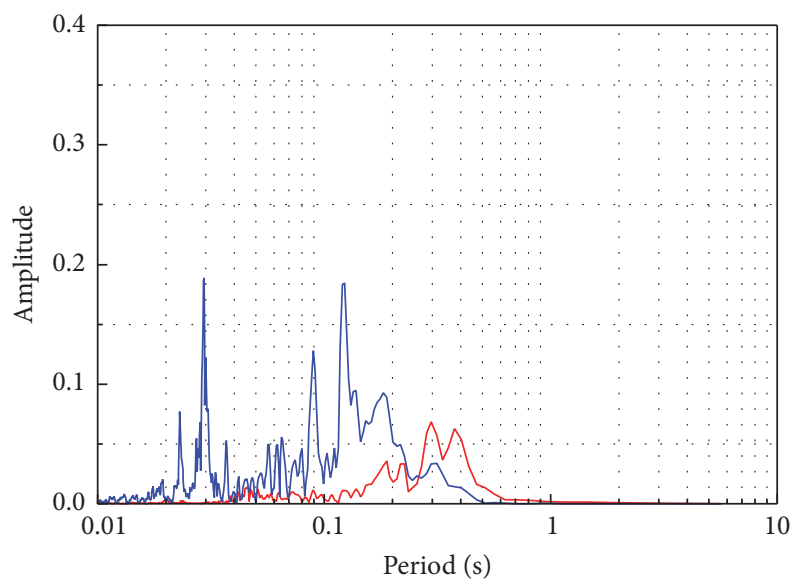

ISO
- FIX

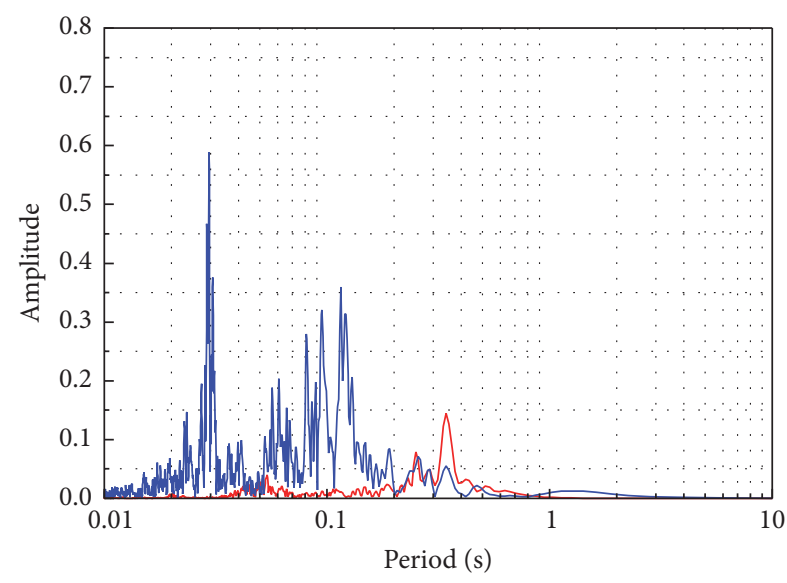

- ISO

- FIX

(b) LWD

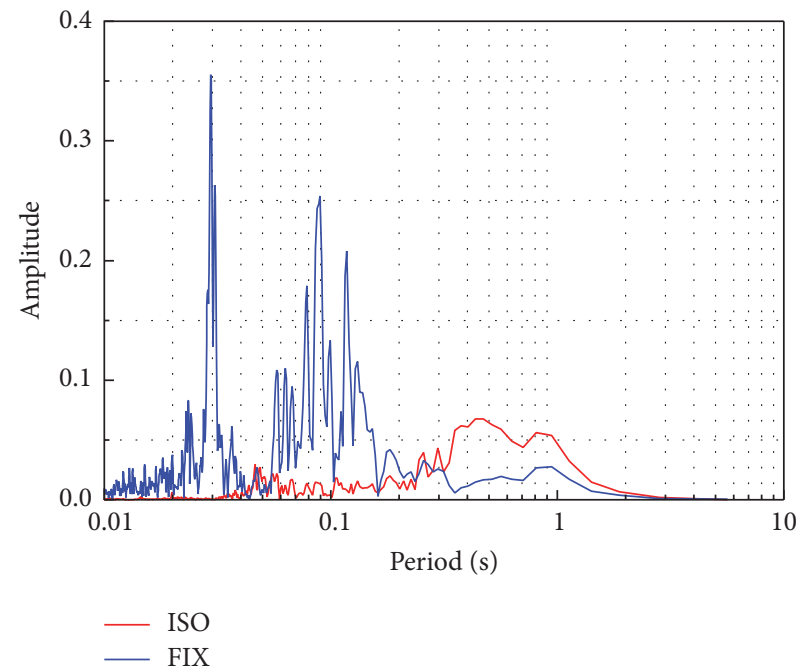

(d) ART

Figure 17: Comparisons on Fourier amplitude spectra of roof acceleration time history of the isolated and fixed structure under major earthquake in direction $x$.

quakes input are shown in Figures 21, 22, and 23. Seismic vibrations are mainly dissipated by plastic deformations of LRBs and that is why deformations of superstructure are relatively much smaller. The isolated model mainly oscillates under its first modal shape due to isolation effect. With increase of input earthquakes, deformations of isolation layer arise remarkably, in order to meet the requirement of bearings plastic deformation to dissipate input seismic energy. For different earthquake waves, isolation displacement responses of TJ and ART waves are much larger than that of EL and LWD waves under three level earthquakes; that is due to the much more long period components in wave TJ and ART, as shown in Figure 17.

The peak interstorey drift ratios (defined as the ratio of the peak interstorey drift and storey height) for isolated and fixed structures subjected to three level excitations are plotted in Figure 24, which is a crucial factor to assess structural damage. As specified in the CSDB, the limit value of elastic story drift for structure under minor earthquake is $1 / 550$, and the limit value of elastoplastic story drift under major earthquake is $1 / 100$.

In the test, the input earthquake level for isolated model was designed as intensity 8 and the earthquake for fixed model was designed as intensity 7 according to the CSDB. As shown, the interstorey drift ratios of isolated model are still less than that of fixed model, which are much more obvious with moderate and major earthquake input. With minor earthquake input, the storey drift ratios of both models are much less than the elastic limit value, which indicates that both models are in elastic condition and no damage happened. As input earthquake increases, the differences of storey drift ratios become much more notable. For major earthquake, the storey drift ratios of both models are still less than the elastoplastic limit value and no severe damage 

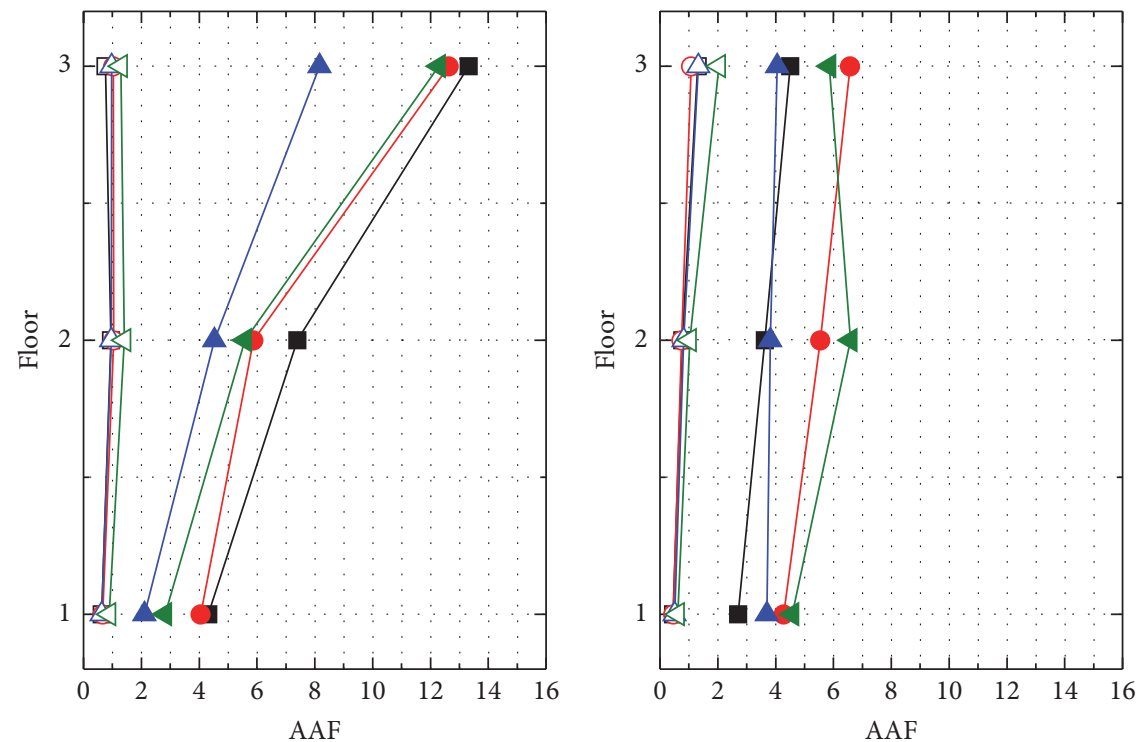

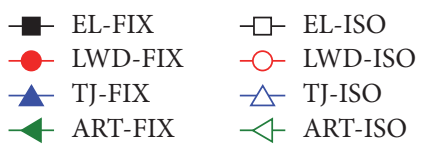

(a)

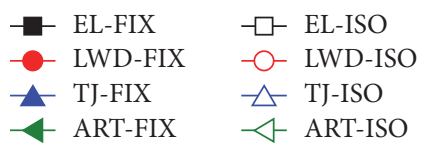

(b)

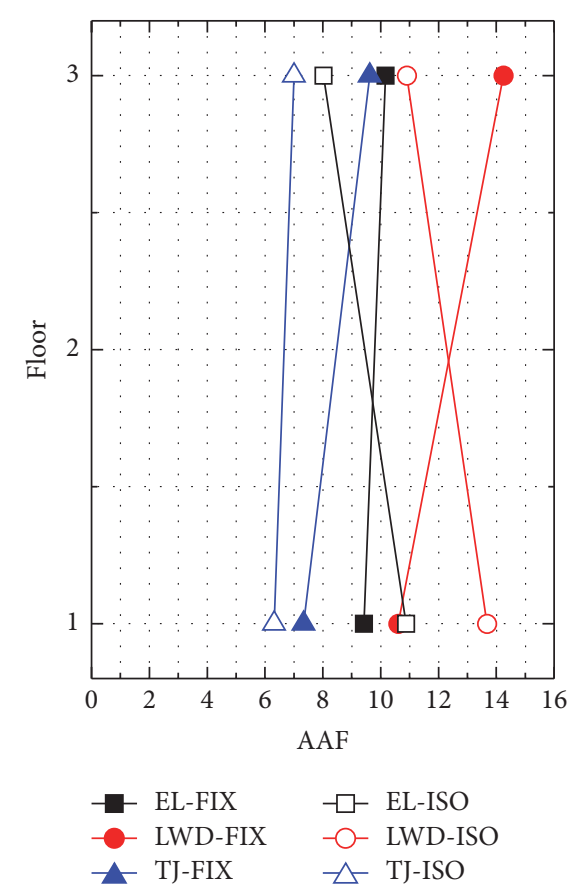

(c)

FIGURE 18: Comparisons on profiles of "Treasures fill the house" AAFs for the isolated and fixed structure under minor earthquake: (a) direction $x$; (b) direction $y$; and (c) direction $z$.

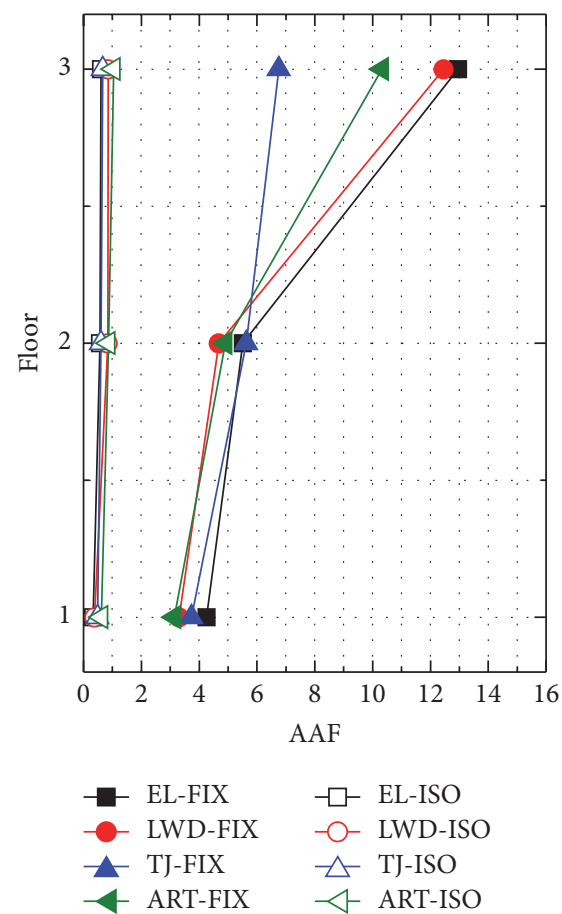

(a)

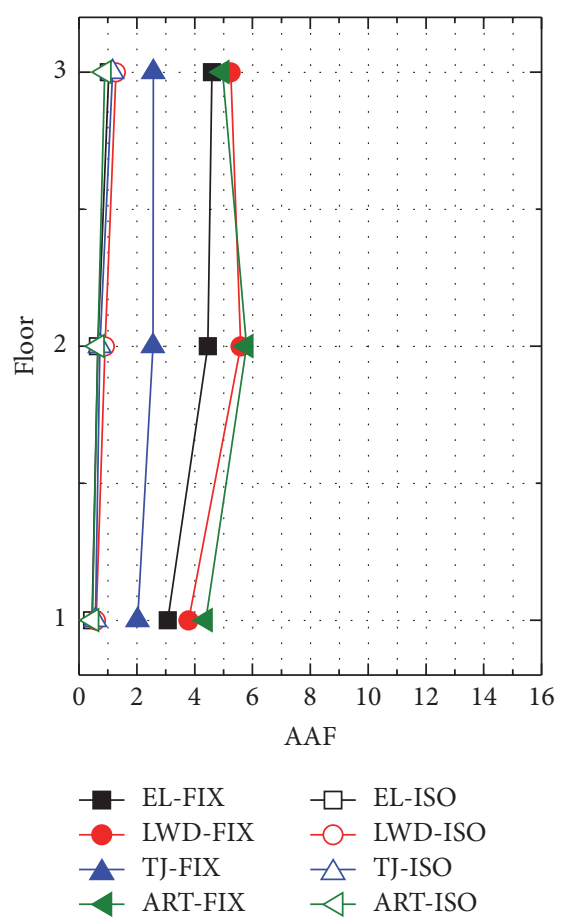

(b)

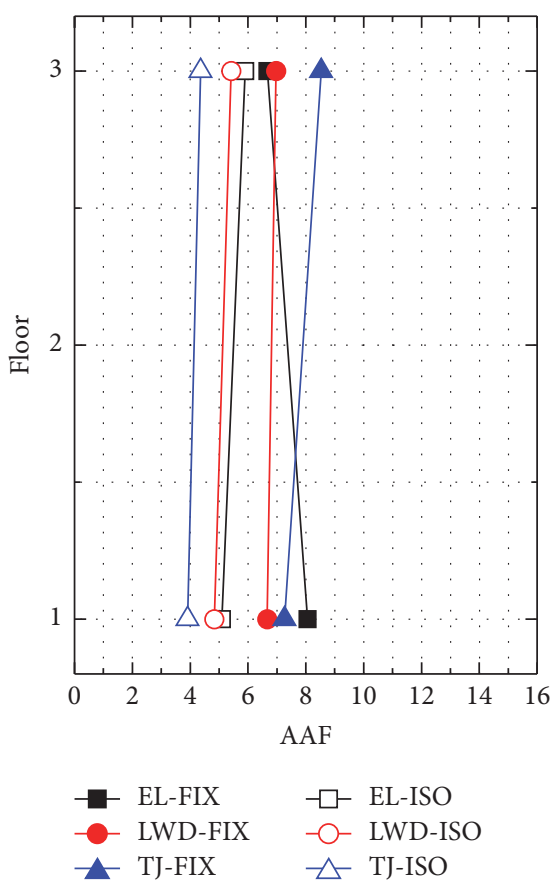

(c)

FIGURE 19: Comparisons on profiles of "Treasures fill the house" AAFs for the isolated and fixed structure under moderate earthquake: (a) direction $x$; (b) direction $y$; and (c) direction $z$. 


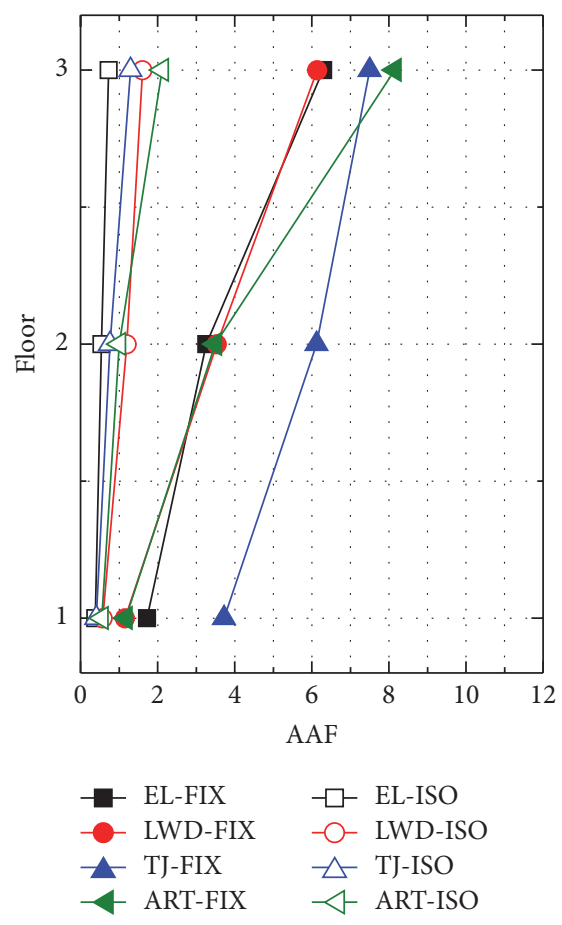

(a)

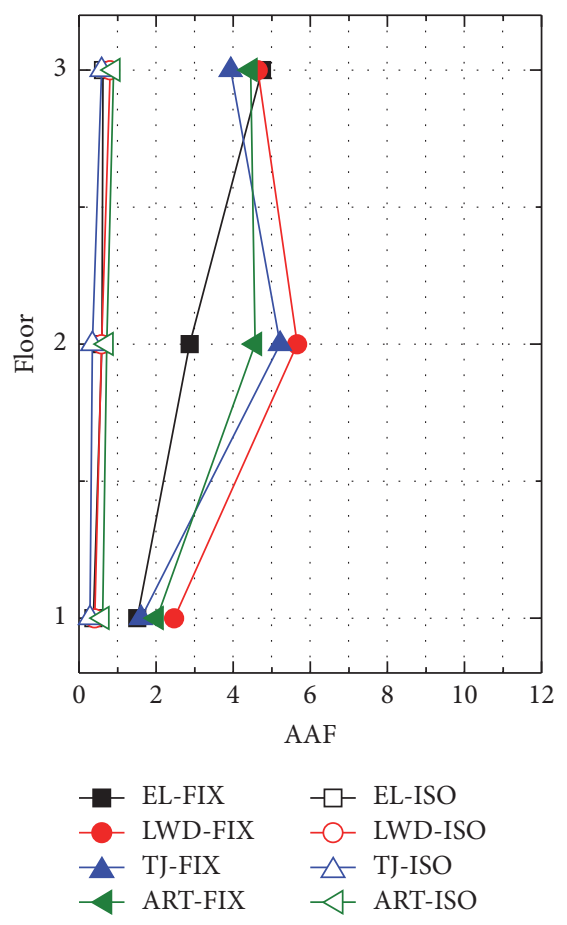

(b)

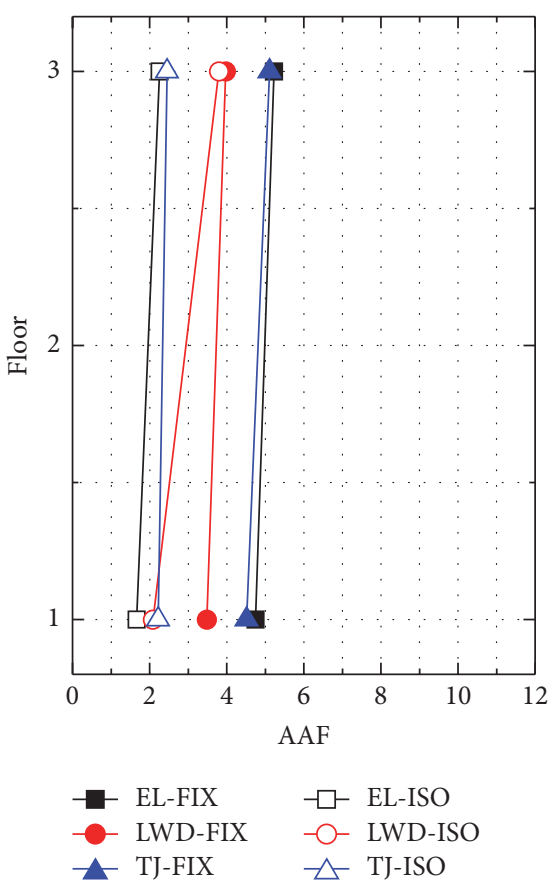

(c)

FIGURE 20: Comparisons on profiles of "Treasures fill the house" AAFs for the isolated and fixed structure under major earthquake: (a) direction $x$; (b) direction $y$; and (c) direction $z$.

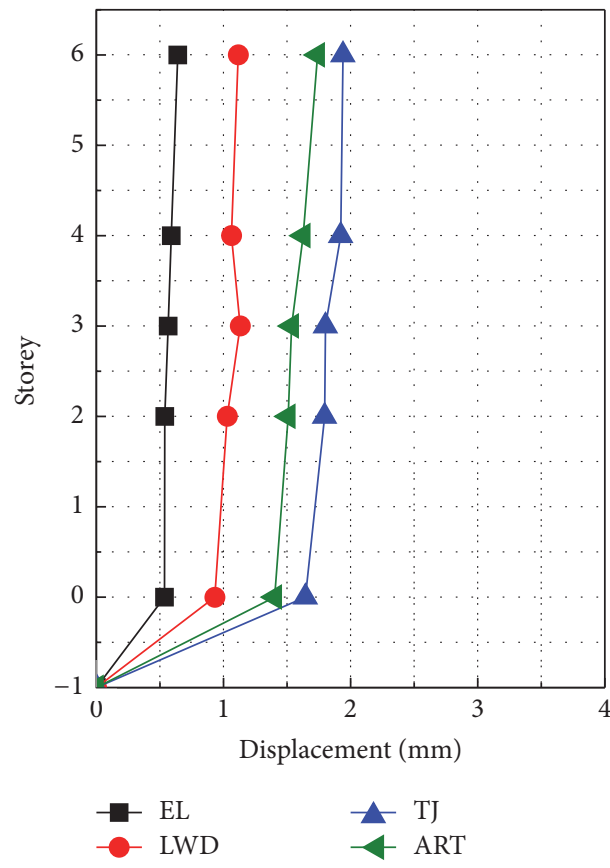

(a)

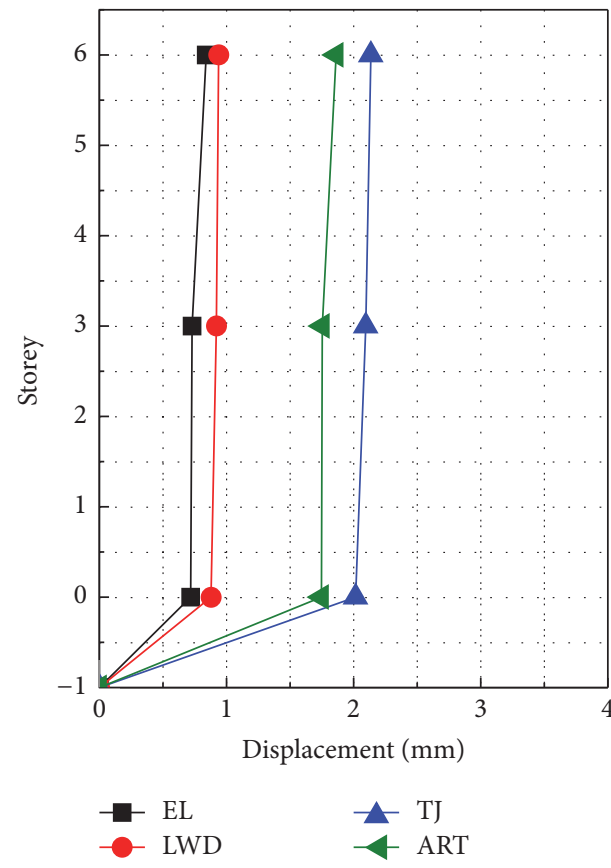

(b)

Figure 21: Profiles of maximum storey displacements of isolated structure under minor earthquakes: (a) direction $x$; (b) direction $y$.

occurred in the structure. It could be found that, under major earthquake, the storey drift ratio of isolated model is still less than the limit value of elastic story drift, and the isolation effect is remarkable.
4.4. Seismic Responses for Isolation Layer. A series of bearing force-displacement curves under different level intensity ground motions are shown in Figure 25. For each earthquake wave, bearing hysteresis curves become full with seismic 


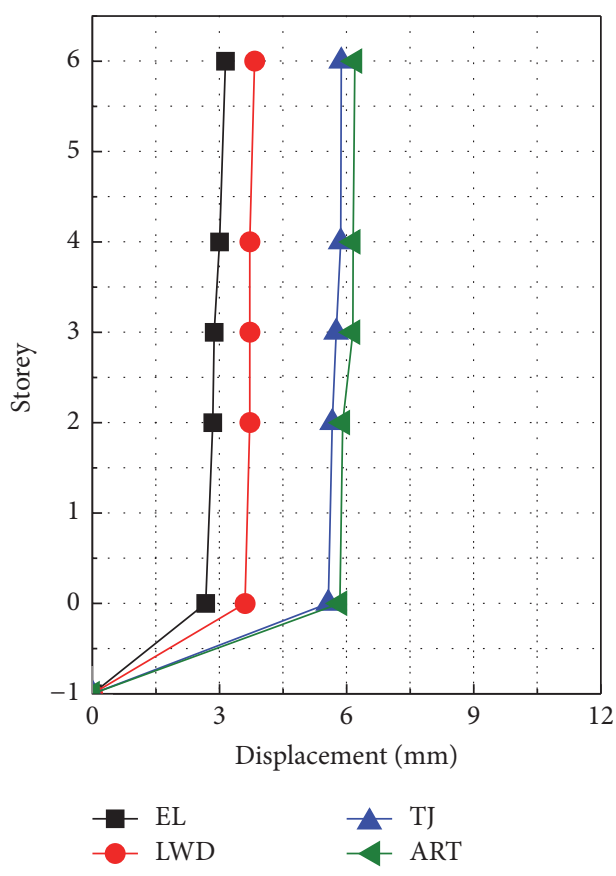

(a)

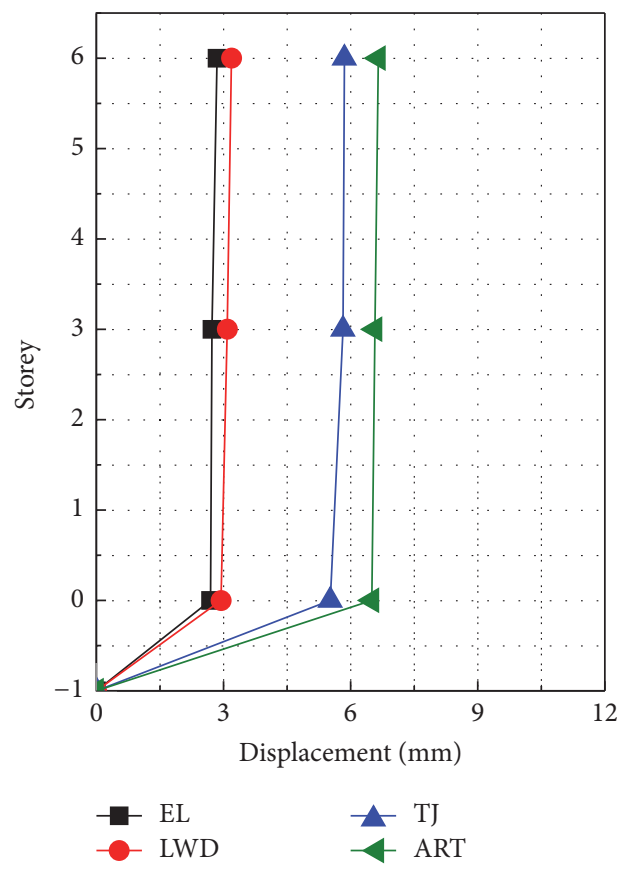

(b)

FIGURE 22: Profiles of maximum storey displacements of isolated structure under moderate earthquakes: (a) direction $x$; (b) direction $y$.

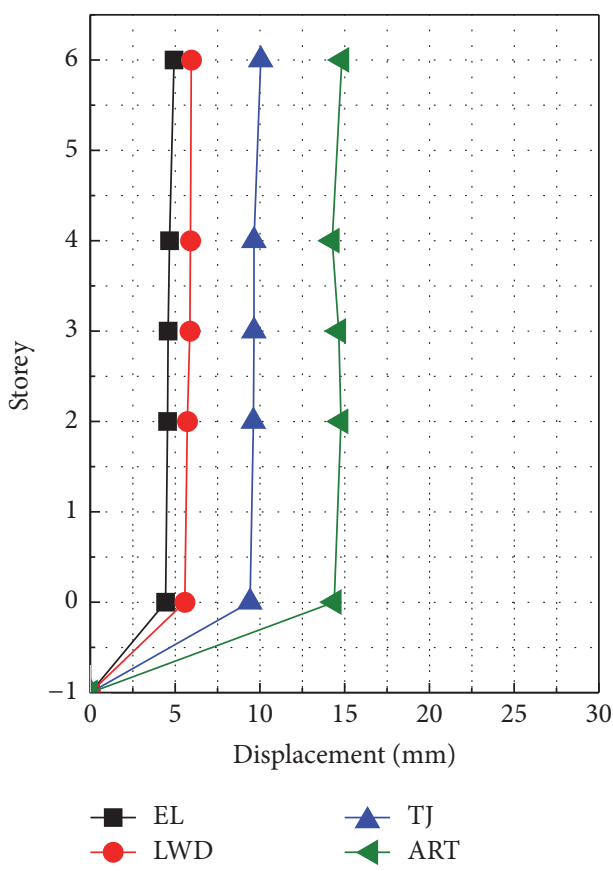

(a)

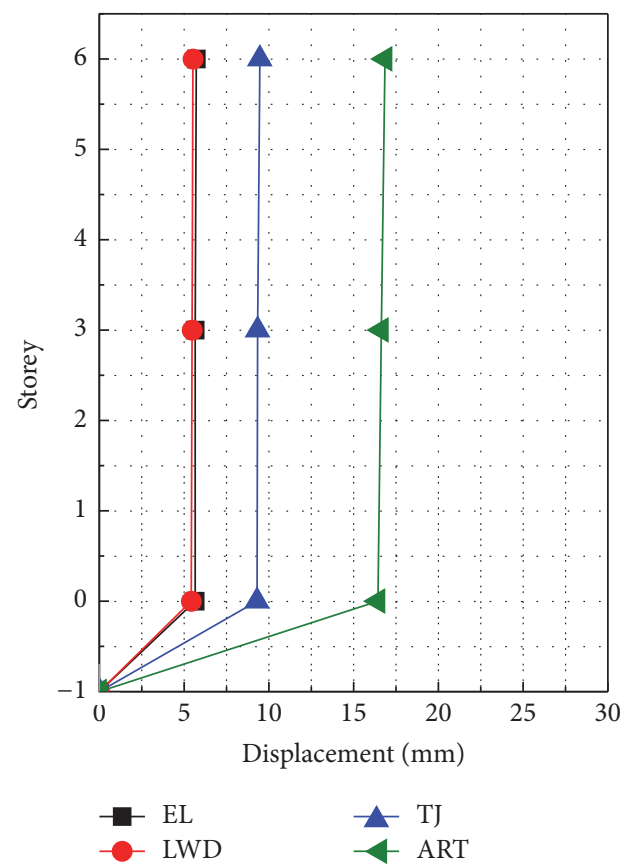

(b)

FIGURE 23: Profiles of maximum storey displacements of isolated structure under major earthquakes: (a) direction $x$; (b) direction $y$.

input level arising. As shown, isolation bearings work well and seismic energy is fully absorbed. It is found that hysteresis curves of waves TJ and ART are much larger than that of waves EL and LWD, and that is mainly because of more long period components in the former two waves, as mentioned above.

As shown in Table 13, with minor, moderate, and major earthquake inputs, the average torsional angles of isolation 


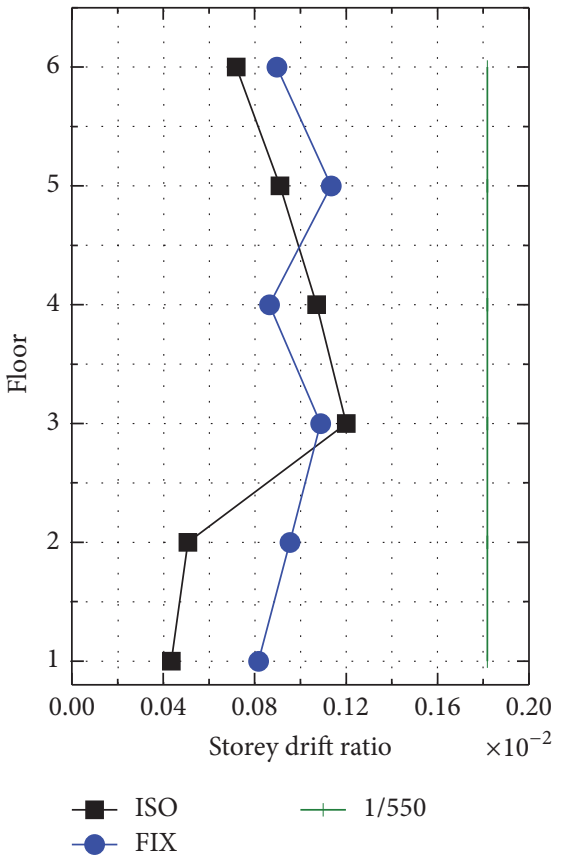

(a)

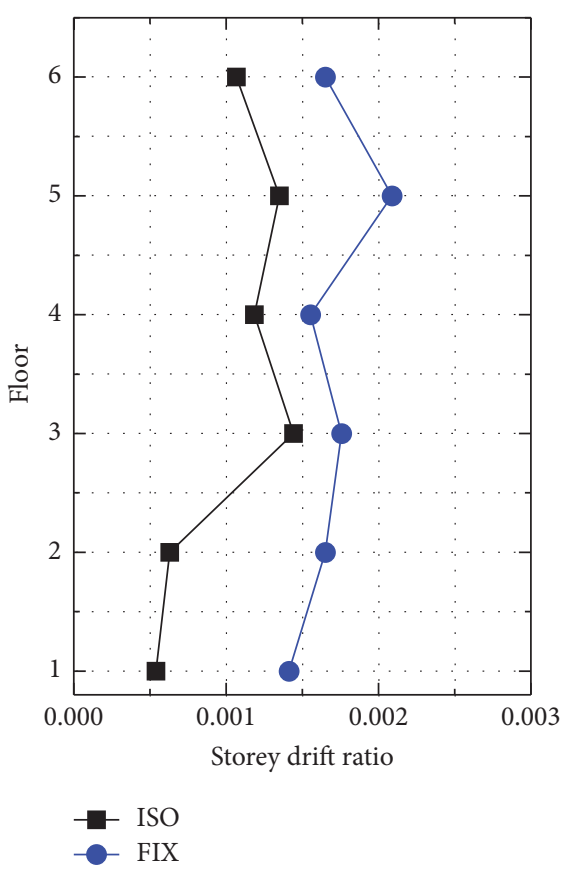

(b)

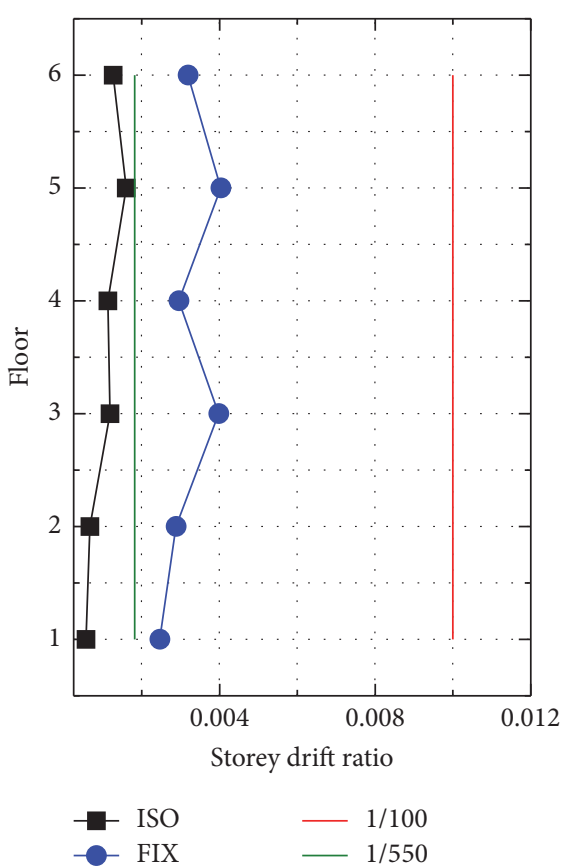

(c)

FIGURE 24: Story drift ratios of superstructure under earthquakes of different intensities: (a) minor earthquake; (b) moderate earthquake; and (c) major earthquake.

TABLE 13: Isolation layer torsion angle under different intensities.

\begin{tabular}{ccccc}
\hline Direction & Case & Minor & Moderate & Major \\
\hline \multirow{4}{*}{$x$} & EL & $1 / 7704$ & $1 / 4897$ & $1 / 3625$ \\
& LWD & $1 / 5942$ & $1 / 3635$ & $1 / 3698$ \\
& TJ & $1 / 4390$ & $1 / 3372$ & $1 / 4355$ \\
& ART & $1 / 8496$ & $1 / 5724$ & $1 / 1817$ \\
\hline \multirow{4}{*}{$y$} & AVE & $1 / 6215$ & $1 / 4208$ & $1 / 3016$ \\
\hline & EL & $1 / 6698$ & $1 / 3731$ & $1 / 1915$ \\
& LWD & $1 / 4651$ & $1 / 1991$ & $1 / 1991$ \\
& TJ & $1 / 5147$ & $1 / 2235$ & $1 / 1773$ \\
& ART & $1 / 6983$ & $1 / 2189$ & $1 / 900$ \\
\hline & AVE & $1 / 5700$ & $1 / 2389$ & $1 / 1482$ \\
\hline
\end{tabular}

layer are, respectively, $1 / 6215,1 / 4208$, and $1 / 3016$ in direction $x$ and $1 / 5700,1 / 2389$, and $1 / 1482$ in direction $y$, which indicates that the isolated model mainly oscillates with its first mode, and the torsional responses are not significant. The isolation design of the museum is stable to support superstructure.

\section{Conclusions}

Shaking table tests for the New Yunnan Provincial Museum with and without base isolators were conducted and the model was subjected to earthquake actions representing minor, moderate, and major earthquakes for a region of moderate seismicity, with basic seismic intensity at the 8 degrees. From the test results the following conclusions can be drawn:

(1) The interstorey drift ratios of isolated structure are all less than the elastic and elastoplastic limits specified in the CSDB. The museum isolated model remains in elastic state without any damage occurring under minor earthquake and no severe damage happened with major earthquake input.

(2) Compared with the test results of isolated and basefixed structures, significant differences are experimentally observed in the acceleration and story drift responses. The acceleration amplification factors (AAFs) for the isolated structure under three level ground motions are all less than 1. Acceleration responses of the "Treasures fill the house," composed of steel truss and suspension system, are effectively reduced by isolation bearings.

(3) The isolation bearings exhibit full hysteretic curves and the input seismic energy is well dissipated. The efficiency of the isolation system varies with different earthquakes, which is better for high-frequency waves such as EL wave. Base isolation provides outstanding seismic performances for this complex museum structure under different level earthquakes.

\section{Competing Interests}

The authors declare that they have no competing interests. 

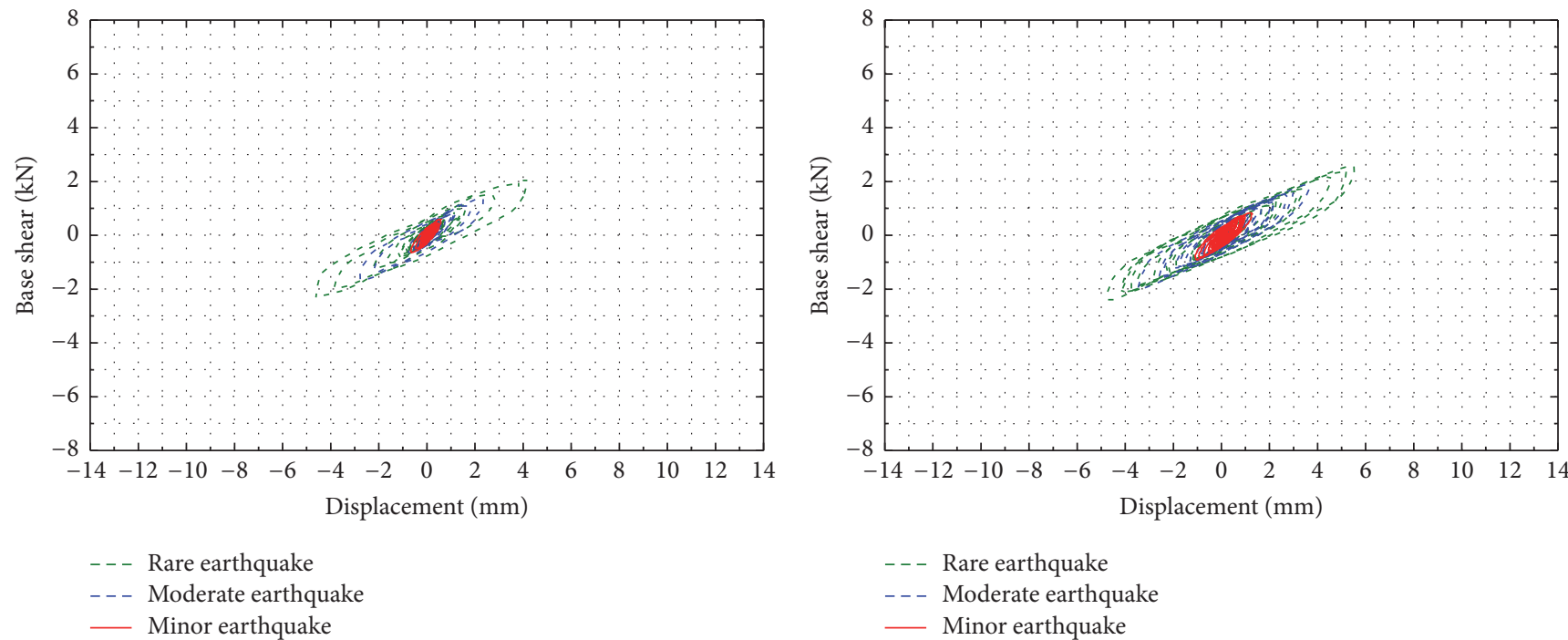

(a)
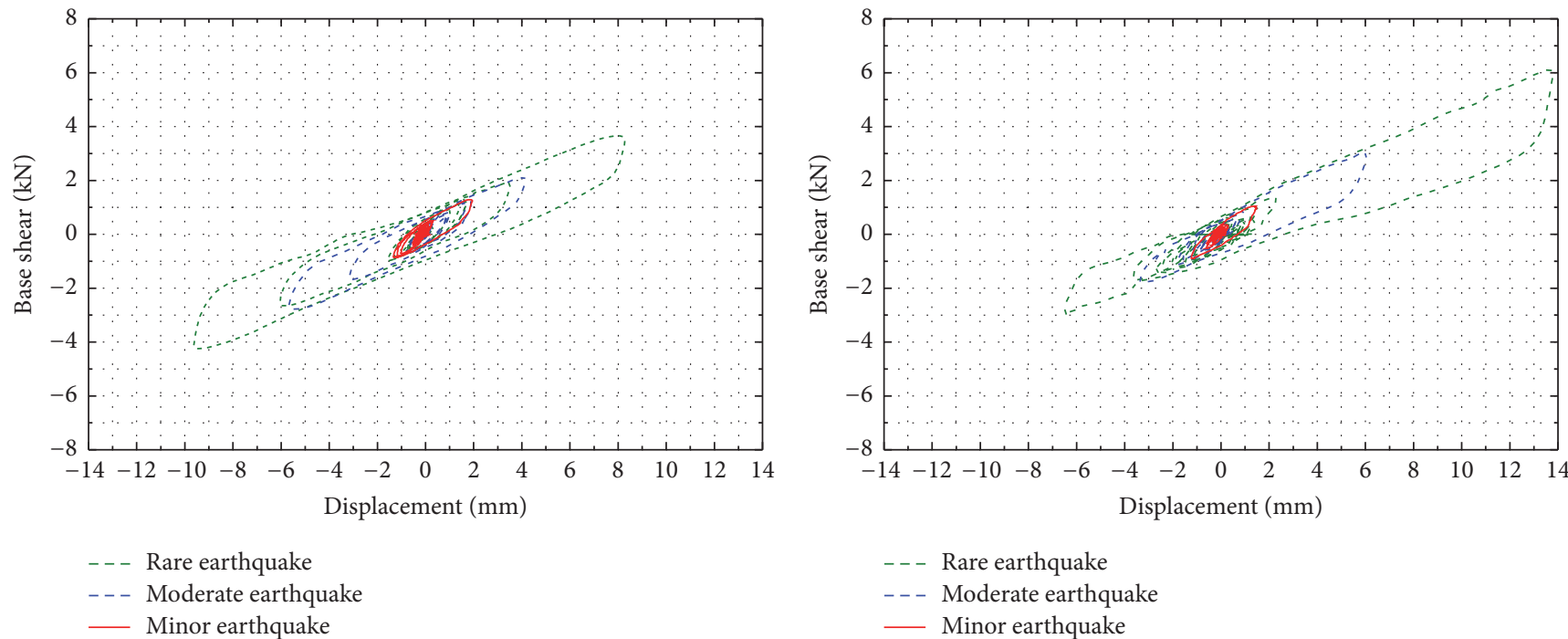

(c)

(d)

FIgURE 25: Typical hysteretic curves of LRB: (a) EL wave, (b) LWD wave, (c) TJ wave, and (d) ART wave.

\section{Acknowledgments}

The writers gratefully acknowledge the financial support of the National Natural Science Foundation of China (Grant nos. 51478257, 51308331, and 51508414), Natural Science Foundation of Shanghai (Grant no. 15ZR1416200), and Research Fund for the Doctoral Program of Higher Education of China (Grant no. 20133108110024).

\section{References}

[1] T. Sasaki, E. Sato, K. L. Ryan, T. Okazaki, S. A. Mahin, and K. Kajiwara, "NEES/E-defense base-isolation tests: effectiveness of friction pendulum and lead-rubber bearing systems," in Proceedings of the 15th World Conference of Earthquake Engineering, 2012.
[2] Y. Liu, W.-G. Liu, X. Wang, W.-F. He, and Q.-R. Yang, "New equivalent linear impact model for simulation of seismic isolated structure pounding against moat wall," Shock and Vibration, vol. 2014, Article ID 151237, 10 pages, 2014.

[3] S. Nagarajaiah and S. Xiaohong, "Response of base-isolated usc hospital building in northridge earthquake," Journal of Structural Engineering, vol. 126, no. 10, pp. 1177-1186, 2000.

[4] F. Naeim and J. M. Kelly, Design of Seismic Isolated Structures: From Theory to Practice, John Wiley \& Sons, New York, NY, USA, 1999.

[5] J. P. Stewart, J. P. Conte, and I. D. Aiken, "Observed behavior of seismically isolated buildings," Journal of Structural Engineering, vol. 125, no. 9, pp. 955-964, 1999.

[6] E. G. Fischer and T. P. Fischer, "Quasi-resonance effects observed in the 1994 Northridge earthquake, and others," Shock and Vibration, vol. 5, no. 3, pp. 153-158, 1998. 
[7] W. H. Robinson, "Recent research and applications of seismic isolation in New Zealand," Bulletin of the New Zealand National Society for Earthquake Engineering, vol. 28, no. 4, pp. 253-264, 1995.

[8] B. Myslimaj, S. Gamble, D. Chin-Quee, A. Davies, and B. Breukelman, "Base isolation technologies for seismic protection of museum artifacts," in Proceedings of the IAMFA Annual Conference, pp. 21-24, San Francisco, Calif, USA, 2003.

[9] X. Lu, G. Fu, W. Shi, and W. Lu, "Shake table model testing and its application," The Structural Design of Tall and Special Buildings, vol. 17, no. 1, pp. 181-201, 2008.

[10] X. Lu and X. Wu, "Study on a new shear wall system with shaking table test and finite element analysis," Earthquake Engineering and Structural Dynamics, vol. 29, no. 10, pp. 14251440, 2000.

[11] P. Roussis, E. Pavlou, and E. Pisiara, "Base-isolation technology for earthquake protection of art objects," in Proceedings of the 14th World Conference on Earthquake Engineering, Beijing, China, 2008.

[12] S. Sorace and G. Terenzi, "Seismic performance assessment and base-isolated floor protection of statues exhibited in museum halls," Bulletin of Earthquake Engineering, vol. 13, no. 6, pp. 18731892, 2015.

[13] M. Iiba, M. Midorikawa, H. Yamanouchi, S. Yamaguchi, Y. Ohashi, and M. Takayama, "Shaking table tests on performance of isolators for houses subjected to three-dimensional earthquake motions," in Proceedings of the 12th World Conference on Earthquake Engineering, Auckland, New Zealand, 2000.

[14] X. Lu, Y. Zhu, W. Shi, S. Ueda, D. Feng, and T. Miyama, "Shaking table test on building models with combined isolation system," China Civil Engineering Journal, vol. 34, pp. 43-49, 2001.

[15] B. Yoo and Y.-H. Kim, "Study on effects of damping in laminated rubber bearings on seismic responses for a 1/8 scale isolated test structure," Earthquake Engineering \& Structural Dynamics, vol. 31, no. 10, pp. 1777-1792, 2002.

[16] M. Dolce, D. Cardone, F. C. Ponzo, and C. Valente, "Shaking table tests on reinforced concrete frames without and with passive control systems," Earthquake Engineering and Structural Dynamics, vol. 34, no. 14, pp. 1687-1717, 2005.

[17] M. Dolce, D. Cardone, and F. C. Ponzo, "Shaking-table tests on reinforced concrete frames with different isolation systems," Earthquake Engineering and Structural Dynamics, vol. 36, no. 5, pp. 573-596, 2007.

[18] T. A. Rawlinson, J. D. Marshall, K. L. Ryan, and H. Zargar, "Development and experimental evaluation of a passive gap damper device to prevent pounding in base-isolated structures," Earthquake Engineering and Structural Dynamics, vol. 44, no. 11, pp. 1661-1675, 2015.

[19] E. Takaoka, Y. Takenaka, and A. Nimura, "Shaking table test and analysis method on ultimate behavior of slender base-isolated structure supported by laminated rubber bearings," Earthquake Engineering and Structural Dynamics, vol. 40, no. 5, pp. 551-570, 2011.

[20] M. Kikuchi, M. Saruta, K. Tamura, J. M. Kelly, L. D. Aiken, and P. W. Clark, "Earthquake simulator test of a base-isolated reinforced concrete building," Journal of Structural \& Construction Engineering, pp. 69-78, 1994.

[21] J.-S. Hwang and T.-Y. Hsu, "Experimental study of isolated building under triaxial ground excitations," Journal of Structural Engineering, vol. 126, no. 8, pp. 879-886, 2000.

[22] N. Lakshmanan, K. S. Kumar, R. Sreekala, K. Muthumani, J. Guru, and N. Gopalakrishnan, "Experimental investigations on the seismic response of a base-isolated reinforced concrete frame model," Journal of Performance of Constructed Facilities, vol. 22, no. 5, pp. 289-296, 2008.

[23] W.-J. Chung, C.-B. Yun, N.-S. Kim, and J.-W. Seo, "Shaking table and pseudodynamic tests for the evaluation of the seismic performance of base-isolated structures," Engineering Structures, vol. 21, no. 4, pp. 365-379, 1999.

[24] T. Miyama and K. Masuda, "Shaking table tests on base-isolated buildings having high aspect ratios: the tensile force on the rubber bearing and the subsequent setting vibration," Journal of Structural and Construction Engineering, vol. 573, pp. 61-68, 2003.

[25] W. F. He, W. G. Liu, Q. R. Yang, and C. Qin, "Study on dynamic response of large and small aspect ratio isolated buildings," The Structural Design of Tall and Special Buildings, vol. 23, no. 17, pp. 1329-1344, 2014.

[26] K. Kasai, Y. Ooki, S. Motoyui, T. Takeuchi, and E. Sato, "Edefense tests on full-scale steel buildings: part 1-experiments using dampers and isolators," in Proceedings of the ASCE Structures Congress, pp. 16-19, Long Beach, Calif, USA, May 2007.

[27] K. L. Ryan, N. D. Dao, E. Sato, T. Sasaki, and T. Okazaki, "Aspects of isolation device behavior observed from full-scale testing of an isolated building at E-Defense," in Proceedings of the Structures Congress, pp. 25-36, 2012.

[28] S.-H. Oh, S.-H. Song, S.-H. Lee, and H.-J. Kim, "Seismic response of base isolating systems with $\mathrm{U}$-shaped hysteretic dampers," International Journal of Steel Structures, vol. 12, no. 2, pp. 285-298, 2012.

[29] C. O. Azeloglu, A. Edincliler, and A. Sagirli, "Investigation of seismic behavior of container crane structures by shake table tests and mathematical modeling," Shock and Vibration, vol. 2014, Article ID 682647, 9 pages, 2014.

[30] Y. M. Wu and B. Samali, "Shake table testing of a base isolated model," Engineering Structures, vol. 24, no. 9, pp. 1203-1215, 2002.

[31] B. Samali, Y. M. Wu, and J. Li, "Shake table tests on a mass eccentric model with base isolation," Earthquake Engineering \& Structural Dynamics, vol. 32, no. 9, pp. 1353-1372, 2003.

[32] T. J. Paulson, D. P. Abrams, and R. L. Mayes, "Shaking-table study of base isolation for masonry buildings," Journal of Structural Engineering, vol. 117, no. 11, pp. 3315-3336, 1991.

[33] N. Sato, A. Kato, Y. Fukushima, and M. Iizuka, "Shaking table tests on failure characteristics of base isolation system for a DFBR plant," Nuclear Engineering and Design, vol. 212, no. 1-3, pp. 293-305, 2002.

[34] T. Matsui, K. Mizuno, E. Sugiyama, Y. Esaka, and T. Hibino, "Shaking table tests on a seismically-isolated large-span arch supported by base structures," Journal of Structural \& Construction Engineering, pp. 87-94, 2004.

[35] M. Tomaževič, I. Klemenc, and P. Weiss, "Seismic upgrading of old masonry buildings by seismic isolation and CFRP laminates: a shaking-table study of reduced scale models," Bulletin of Earthquake Engineering, vol. 7, no. 1, pp. 293-321, 2009.

[36] Y. Liu, W.-G. Liu, W.-F. He, and Q.-R. Yang, "Shaking table tests for a complex museum's isolated structure," Journal of Vibration and Shock, vol. 33, no. 4, pp. 107-112, 2014.

[37] GB, "Code for seismic design of buildings," GB 50011-2010, National Standard of the People's Republic of China, 2010. 
[38] "Technical specification for concrete structures of tall buildings," Tech. Rep. JGJ3-2002, Profession Standard of the People's Republic of China, 2002.

[39] X. Lu, Y. Zhou, and W. Lu, "Shaking table model test and numerical analysis of a complex high-rise building," Structural Design of Tall and Special Buildings, vol. 16, no. 2, pp. 131-164, 2007.

[40] "Specification of testing methods for earthquake resistant building," Tech. Rep. JGJ101-96, Profession Standard of the People's Republic of China, 1996.

[41] R. Maseki, I. Nagashima, and M. Hisano, "An experimental study on application of hybrid-type base isolation system to high-rise buildings," in Proceedings of the 12th World Conference on Earthquake Engineering, Auckland, New Zealand, 2000.

[42] I. V. Kalpakidis and M. C. Constantinou, "Principles of scaling and similarity for testing of lead-rubber bearings," Earthquake Engineering \& Structural Dynamics, vol. 39, no. 13, pp. 1551-1568, 2010.

[43] X. Lu, Y. Chen, and Y. Mao, "Shaking table model test and numerical analysis of a supertall building with high-level transfer storey," The Structural Design of Tall and Special Buildings, vol. 21, no. 10, pp. 699-723, 2012.

[44] I. V. Kalpakidis and M. C. Constantinou, "Effects of heating on the behavior of lead-rubber bearings. I: theory," Journal of Structural Engineering, vol. 135, no. 12, pp. 1440-1449, 2009.

[45] I. V. Kalpakidis and M. C. Constantinou, "Effects of heating on the behavior of lead-rubber bearings. II: Verification of theory," Journal of Structural Engineering, vol. 135, no. 12, pp. 1450-1461, 2009. 


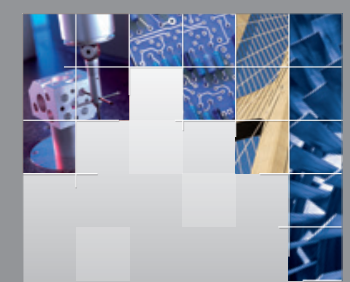

\section{Enfincering}
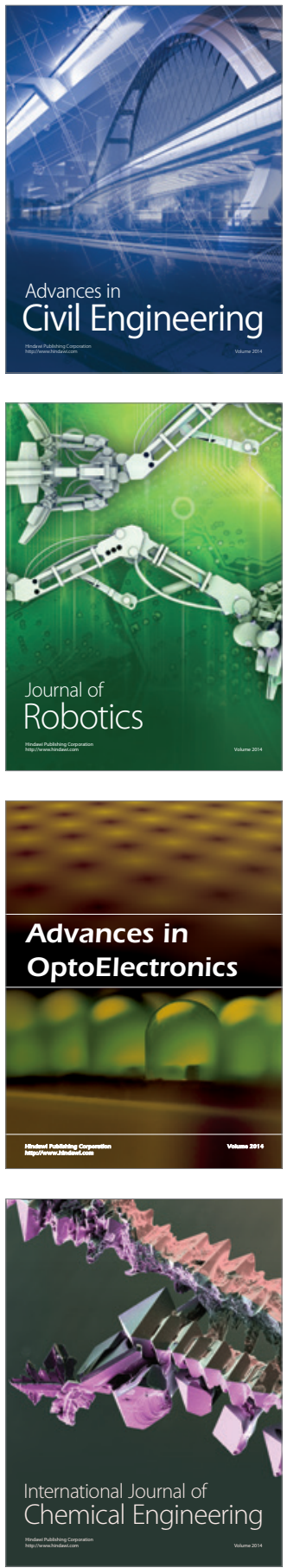

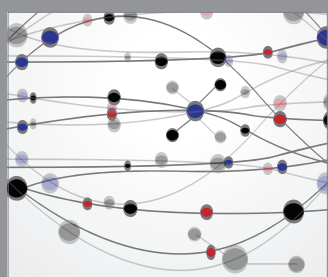

The Scientific World Journal

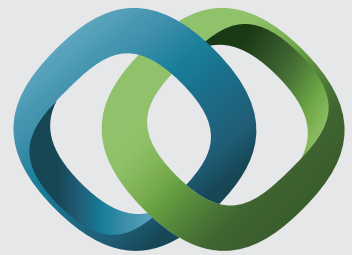

\section{Hindawi}

Submit your manuscripts at

http://www.hindawi.com
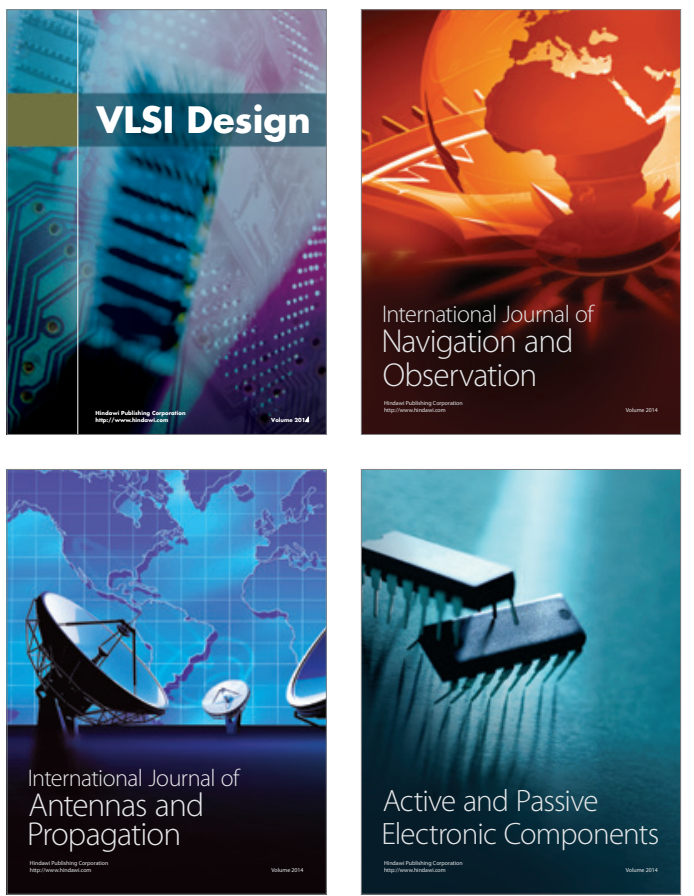
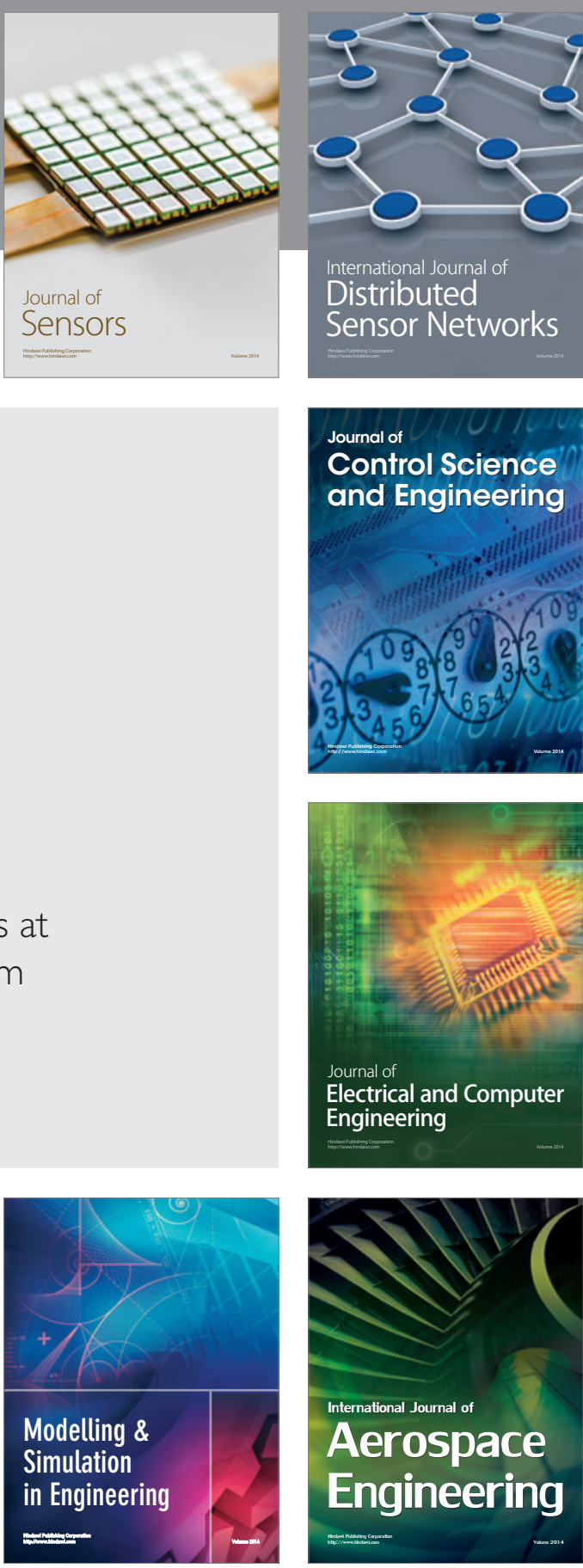

International Journal of

Distributed

Sensor Networks

Journal of

Control Science

and Engineering
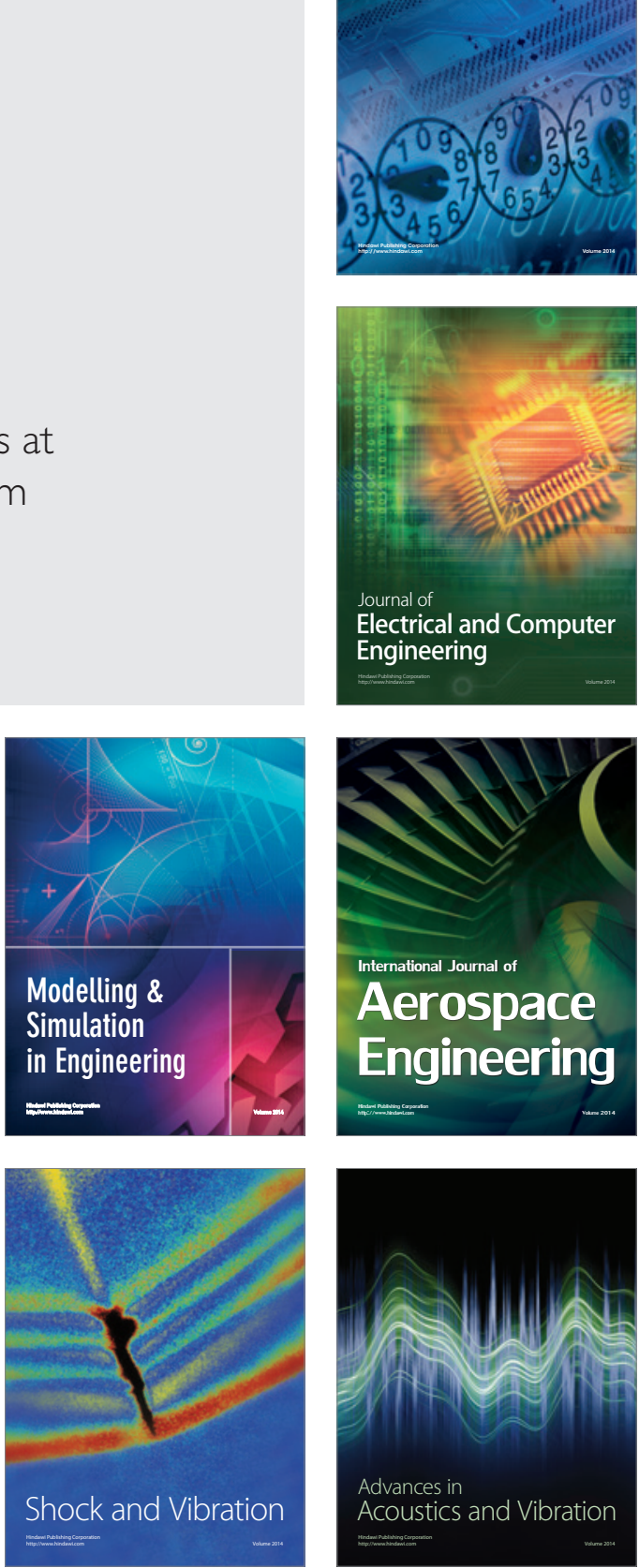